\title{
Về viết và biên tập nghiên cứu chất lượng quốc tế
}

\author{
Vương Quân Hoàng \\ Trường ĐH Thành Tây, Trung tâm ISR \\ Université Libre de Bruxelles, Centre Emile Bernheim
}

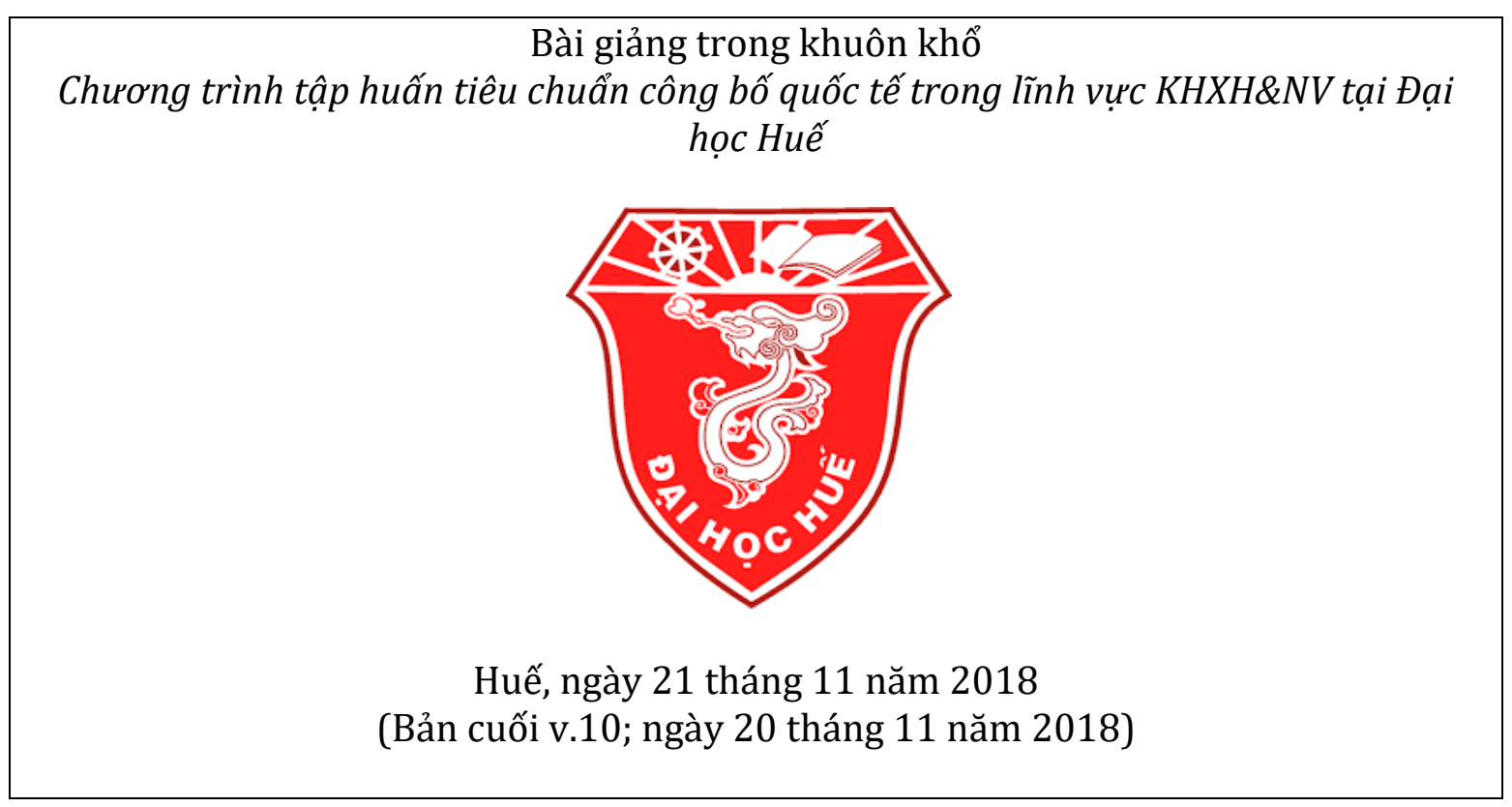

"Well begun is half done"

-Aristotle-

\section{Quyết định biên tập và quyết định của tác giả}

Trong Hình 1, một số trạng thái của bản thảo có thể nhận thấy tường minh. Các trạng thái này phản ánh một phần quá trình quyết định biên tập, ${ }^{1}$ cũng như số phận của bản thảo. Các trạng thái cơ bản như sau:

- Bản thảo đã nộp, đang chờ ban biên tập (từ đây về sau viết tắt là 'BBT') đánh giá chất lượng, quy cách kỹ thuật, và một số tiêu chuẩn biên tập-chúng có thể khác biệt giữa các nhà xuất bản ('NXB'), cũng như giữa các tạp chí của cùng $\mathrm{NXB}$ - cân nhắc bản thảo có gửi đi phản biện hay không.

- Quyết định biên tập 'mốc 0': Từ chối mà không cần gửi đi phản biện ('Desk Reject') hoặc liên lạc để gửi đi phản biện.

- Quá trình phản biện (tạm thời) kết thúc. BBT đánh giá tổng thể bản thảo dựa trên báo cáo phản biện (còn gọi là 'bình duyệt' hoặc 'bình xét'). Quá trình cân

${ }^{1}$ Các quyết định này do bản thân tôi chịu trách nhiệm đưa ra trong vai trò biên tập. 
nhắc này lâu hay nhanh tùy thuộc vào cách thức tổ chức của hệ thống biên tập và quyền lực của $B B T$. Quyền $B B T$ càng nhiều—cũng có nghĩa là trách nhiệm càng lớn-thì quá trình này có xu hướng dài hơn. Ví dụ, quyền của BBT các tạp chí thuộc Nature rất lớn, nên thời gian đánh giá các báo cáo này và cân nhắc quyết định khá dài, có thể lên đến 3-4 tuần.

- Quyết định biên tập đầu tiên: Outright Accept / Minor Revision / Major Revision / Reject (và có thể được khuyến khích nộp lại sau khi sửa). Trường hợp 'Outright Accept' khá hiếm hoi. Quyết định 'Minor Revision' cũng là tỷ lệ tương đối nhỏ, vì cơ bản có thể tiên liệu khả năng số phận tười sáng nếu sửa tốt. Phần lớn hơn cả rơi vào 'Major Revision' và 'Reject'. Trong một số trường hợp, khi các báo cáo khác biệt quá nhiều, BBT có thể đóng vai trò điều hòa: Mời thêm người bình xét bổ sung.

- Quyết định đáng kể nhất của tác giả thường cân nhắc khi nhận được yêu cầu 'Major Revision': có tiến hành sửa hay không. Nếu không sửa thì có thể quyết định rút bài, là dòng thứ 5 trong Hình 1 (trạng thái: Manuscript withdrawn).

- Sau khi tác giả sửa và nộp lại, BBT sẽ cân nhắc. Với Minor, có thể sẽ không cần lượt phản biện tiếp theo, hoặc cần, tùy vào đánh giá mức độ hoàn thành và chất lượng. Với Major, chắc chắn sẽ gửi ra phản biện tiếp. Những người phản biện vòng tiếp theo có thể chính là người đã phản biện lượt đầu, hoặc là người mới, tùy thuộc nhiều yếu tố (như thời gian của người biên tập, chính sách BBT muốn quan điểm mới).

- Với Major, có thể xuất hiện vòng lặp vài lần, đặc biệt khi số lượng người bình duyệt bản thảo nhiều, ví dụ > 3, và ý kiến sai khác. Về cơ bản, chỉ cần còn 1 ý kiến cho rằng Major, thì trạng thái chung vẫn là Major, mặc dù có thể các ý kiến khác cho là Minor. Đôi khi, chỉ vì 1 ý kiến đủ mạnh, thì vẫn có thể bị Reject sau vài lượt sửa bài.

- Quyết định biên tập cuối cùng: 'Accept'. Tác giả sẽ nhận được thư chúc mừng hân hoan của BBT. Đôi khi thư này vẫn kèm theo yêu cầu sửa một số thứ nho nhỏ, thiên về kỹ thuật biên tập, gọi là 'Conditional Acceptance'. Việc sửa ở khâu này không liên quan tới các cây bút bình xét nữa, mà thường là một số chi tiết thuộc về kỹ thuật làm bản thảo, và không có gì đáng lo ngại.

- Sau quyết định biên tập, và những sửa nhỏ chi tiết, bản thảo sẽ được chuyển đi để sản xuất, và chờ ngày xuất bản chính thức. Ngày nay, phần lớn các ấn phẩm chú trọng xuất bản điện tử (online). Ví dụ thông báo sau đây của PNAS lừng danh sau 104 năm in giấy: "On 7/1/19, PNAS will eliminate the strict page limits and the Plus article category. The preferred length of articles will remain at 6 pgs; flexible length limits up to 12 pgs will be allowed. To make this feasible, PNAS will cease producing the print edition as of 1/19".

- Sau một thời gian, BBT hoặc đơn vị sản xuất sẽ gửi lại cho tác giả 'Uncorrected Proof' (trước kia gọi là 'galley proof'), tức là bản sản xuất sơ bộ đã sắp chữ điện tử chuẩn, để sửa lượt cuối. Thường ở đoạn này kèm theo các câu hỏi xác nhận, các lỗi lặt vặt như chính tả, ngữ pháp đơn giản, trích dẫn sai/thiếu, các câu văn được biên tập lại cho rõ nghĩa nhưng cần tác giả xác

\footnotetext{
${ }^{2}$ Thông báo trên Twitter: https://twitter.com/pnasnews/status/1037355107644526599.
} 
nhận, chỉnh sửa tên người và tên cơ quan, v.v.. Đây là các quyết định từ phía tác giả, và sau lượt này, sẽ không thể sửa gì nữa, mà chỉ còn chờ bản sản xuất cuối cùng. Mọi sửa đổi sau đó, đều phải có 'Correction Note' theo quy tắc liêm chính học thuật hiện hành.

- Sau khi xuất bản, còn một loại quyết định của tác giả và BBT nữa, mà rất ít ai 'muốn gặp': quyết định rút bài! Có hai loại rút bài cơ bản: a) Tác giả tự xin rút bài vì nhiều lý do. Phổ biến nhất là do tự tìm thấy sai sót lớn, khiến kết quả cho dù có công bố cũng không đem lại lợi ích khoa học; hoặc có tranh chấp về bản quyền, nguồn gốc dữ liệu, hoặc quyền sử dụng dữ liệu. b) Công bố bị phát hiện có những dấu hiệu vi phạm hành vi nghiên cứu, gọi chung là 'misconduct': ngụy tạo dữ liệu, sửa dữ liệu hoặc cắt ghép không đảm bảo chuẩn mực, tiến hành các nghiên cứu không được phép, sử dụng lại các thông tin và tài nguyên bất hợp lệ (không trích dẫn, không xin phép, v.v..).

Các quyết định trên, và do đó là toàn bộ chu trình, nhanh hay lâu sẽ tùy thuộc phong cách của NXB, mức độ hiệu quả xử lý bản thảo của BBT, cũng như đội ngũ cây bút bình duyệt mà tạp chí có khả năng huy động.

Hình 1. Ví dụ về một số trạng thái bản thảo nộp ở các mốc quyết định biên tập Under Processing (1) | Finalizing (0) | Published (2) | Rejected \& Archived (3)

\begin{tabular}{|c|c|c|c|c|c|c|}
\hline I全 & Special Issue/Section & Title & Status & $\begin{array}{l}\text { Submission } \\
\text { Date }\end{array}$ & $\begin{array}{l}\text { Review } \\
\text { Reports }\end{array}$ & $\begin{array}{c}\text { Editor } \\
\text { Decisions }\end{array}$ \\
\hline id anwar * & $\begin{array}{l}\text { S: Sustainable Urban } \\
\text { and Rural } \\
\text { Development } \\
\text { SI: Social Public } \\
\text { Health System and } \\
\text { Sustainability }\end{array}$ & $\begin{array}{l}\text { Urbanization, Urbanicity and } \\
\text { health }\end{array}$ & $\begin{array}{l}\text { Rejected } \\
\text { by editor }\end{array}$ & 13 Nov 2018 & $\begin{array}{l}\text { review } \\
\text { report }\end{array}$ & \\
\hline 1, Ming ZHAO & $\begin{array}{l}\text { S: Sustainable Urban } \\
\text { and Rural } \\
\text { Development } \\
\text { SI: Social Public } \\
\text { Health System and } \\
\text { Sustainability }\end{array}$ & $\begin{array}{l}\text { Data center medical information } \\
\text { management based on big data } \\
\text { smart cities in China }\end{array}$ & $\begin{array}{l}\text { Pending } \\
\text { major } \\
\text { revisions }\end{array}$ & 19 Oct 2018 & $\begin{array}{l}\text { review } \\
\text { reports }\end{array}$ & \\
\hline Inie Sylvester & $\begin{array}{l}\text { S: Sustainable Urban } \\
\text { and Rural } \\
\text { Development } \\
\text { Sl: Social Public } \\
\text { Health System and } \\
\text { Sustainability }\end{array}$ & $\begin{array}{l}\text { Depression, Emotional } \\
\text { Intelligence and Women Health } \\
\text { Status: A Case of Pakistan }\end{array}$ & $\begin{array}{l}\text { Rejected } \\
\text { by editor }\end{array}$ & 18 Oct 2018 & $\begin{array}{l}\text { review } \\
\text { report }\end{array}$ & \\
\hline četić, Goran & $\begin{array}{l}\text { S: Sustainable Urban } \\
\text { and Rural } \\
\text { Development } \\
\text { SI: Social Public } \\
\text { Health System and } \\
\text { Sustainability }\end{array}$ & $\begin{array}{l}\text { Sleep duration and sleep quality } \\
\text { as predictors of health in elderly } \\
\text { individuals }\end{array}$ & $\begin{array}{l}\text { Website } \\
\text { online }\end{array}$ & 4 Oct 2018 & $\begin{array}{l}\text { review } \\
\text { reports }\end{array}$ & decision \\
\hline ang & $\begin{array}{l}\text { S: Sustainable Urban } \\
\text { and Rural } \\
\text { Development } \\
\text { SI: Social Public } \\
\text { Health System and }\end{array}$ & $\begin{array}{l}\text { Optimizing the Strategy of } \\
\text { Privacy Investment in mHealth } \\
\text { under an Incentive Mechanism } \\
\text { using Evolutionary Game }\end{array}$ & $\begin{array}{l}\text { Manuscript } \\
\text { withdrawn }\end{array}$ & 30 Sep 2018 & $\begin{array}{l}\text { review } \\
\text { reports }\end{array}$ & decisions \\
\hline
\end{tabular}

Chu trình như trên dẫn đến một số ngụ ý đối với tác giả nộp bài, trong quan hệ với công tác biên tập. 


\subsection{Quản lý thời gian suốt quá trình}

Thời gian dài ngắn của hành trình từ khi nộp bản thảo đến khi nghiên cứu được "cấp giấy khai sinh" trong đời sống khoa học quốc tế dao động rất nhiều. Phổ biến từ vài tuần tới vài tháng, nhưng đôi khi kéo dài tới vài năm.

Việc chủ động quản lý thời gian suốt quá trình này có ý nghĩa hạn chế tác động của ức chế tâm lý do sự chờ đợi thụ động. Vài cách tương đối chủ động là: a) Suy đoán về trạng thái tiếp theo và các bước công việc chuẩn bị; b) Tiếp tục với công việc nghiên cứu khác.

Chúng ta cùng xét mốc thời gian ở Hình 2 của các tạp chí Nature dưới đây. Cột số đầu tiên là mốc 0 (quyết định biên tập vòng đầu, trước khi gửi đi bình duyệt). Cột tiếp theo là thời gian để có quyết định biên tập đầu tiên (mốc 1) sau bình duyệt. Cột cuối là thời gian tới Accept (nếu được chấp thuận công bố).

Hình 2. Thời gian đến các mốc quyết định biên tập quan trọng của Nature

\begin{tabular}{llll} 
Nature & 9 & 43 & 193 \\
\hline Nature Astronomy & 9 & 36 & 123 \\
\hline Nature Biomedical Engineering & 4 & 52 & 209 \\
\hline Nature Biotechnology & 7 & 51 & 205 \\
\hline Nature Cell Biology & 8 & 47 & 192 \\
\hline Nature Chemical Biology & 8 & 47 & 183 \\
\hline Nature Chemistry & 9 & 49 & 170 \\
\hline Nature Climate Change & 12 & 78 & 218 \\
\hline Nature Communications & 10 & 49 & 189 \\
\hline Nature Ecology \& Evolution & 6 & 47 & 184 \\
\hline Nature Energy & 8 & 55 & 184 \\
\hline Nature Genetics & 5 & 50 & 182 \\
\hline Nature Geoscience & 8 & 63 & 132 \\
\hline Nature Human Behaviour & 7 & 49 & 190 \\
\hline Nature Immumology & 5 & 31 & 119 \\
\hline Nature Materials & 8 & 54 & 229 \\
\hline Nature Medicine & 8 & 50 & 195 \\
\hline Nature Methods & 6 & 56 & 146 \\
\hline Nature Microbiology & 4 & 39 & 160 \\
\hline Nature Nanotechnology & 12 & 61 & 223 \\
\hline Nature Neuroscience & 10 & 54 & 162 \\
\hline Nature Photonics & 12 & 57 & 147 \\
\hline Nature Physics & 7 & 54 & 160 \\
\hline Nature Plants & 7 & 40 & \\
\hline \hline
\end{tabular}

(https://nature.com; truy cập 16-7-2018)

Có thể thấy phổ biến thời gian tới Accept là 5 đến 7 tháng. Nếu tác giả chỉ ngồi ngóng, khoảng thời gian đó sẽ rất dài. Nếu phải xử lý khoảng 2-3 bản thảo khác, hoặc có những công việc chuẩn bị nghiên cứu tiếp, thì thời gian này sẽ trở nên ngắn. 


\section{2. Đối diện với BBT và người phản biện}

Đối với người nộp bài, những vòng cải thiện chất lượng và tranh đấu lý lẽ với BBT và phản biện có ý nghĩa quyết định. Phản biện trong nghiên cứu hiện đại được gọi là 'peer review', với đúng nghĩa của từ này: Một người đồng nghiệp xem xét và đánh giá kết quả của một đồng nghiệp khác.

Như vậy, bản thảo được BBT gửi đi phản biện là một bước tiến lớn. Điều này ngược với suy nghĩ của một số cho rằng đây là bắt đầu quá trình 'hành xác'. Vậy nên mới có Hình 3.

Hình 3. Một cách nghĩ tiêu cực về quá trình phản biện

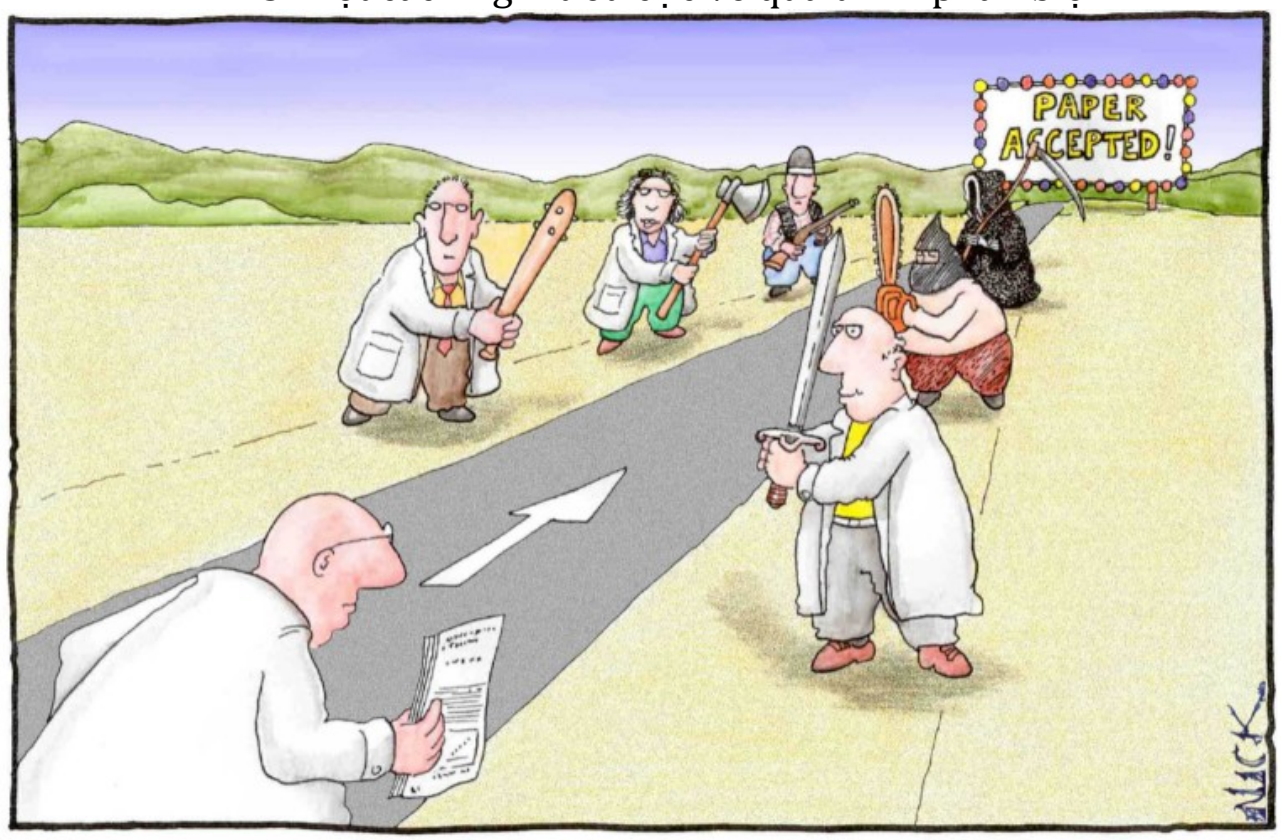

Most scientists regarded the new streamlined peer-review process as 'quite an improvement.'

Tại sao cách nghĩ này bất hợp lý? (Tham khảo: Vuong 2017b.)

Gần đây, theo đánh giá của Publons Clarivate (2018) 2018 Global State of Peer Review, không chỉ công việc bình duyệt là thầm lặng và cô độc, mà thực ra thầm lặng và ít được chú ý nhất chính lại công việc biên tập khoa học. Điều này cũng trái ngược với cảm giác của người nộp bài về quyền lực của BBT trong việc quyết định số phận bản thảo nghiên cứu.

\subsection{Từ suy nghĩ đến hành động: quyền quyết định thuộc về tác giả}

Nhìn ở một góc độ khác, quyền lực của tác giả mới thực sự là lớn. Một khi đã có trong tay kết quả nghiên cứu tốt, được tạo ra sau một quá trình lao động vất vả, công phu, và đảm bảo các tiêu chuẩn học thuật, người quyết định mọi thứ là tác giả. 
Để có quyền lực thực sự này, tác giả luôn phải hoàn thành 2 việc: suy nghĩ + hành động, cụ thể là đối với chương trình nghiên cứu của mình, và cụ thể hơn nữa là bản thảo nghiên cứu có khả năng về đích cao nhất. Tuy vậy, thường xuyên có 2 trường hợp sau xảy ra:

- Suy nghĩ rất nhiều, mà không bắt tay vào hành động

- Hành động rất nhiều, mà không có thời gian suy nghĩ đủ

Trường hợp thứ nhất sẽ dẫn đến tình trạng khan hiếm (hoặc không có) kết quả. Trường hợp thứ hai có thể dẫn đến kết quả yếu, hoặc không có ý nghĩa mấy.

Giả sử quyết định của tác giả là sẽ suy nghĩ thấu đáo, và làm việc chăm chỉ, thì khả năng thành công liệu có tăng lên nhiều? Câu trả lời khá hiển nhiên: Có thể nói với quyết định này, khả năng thành công gần như là biến cố chắc chắn.

\section{Mong muốn của tác giả}

Câu chuyện các quyết định biên tập nói trên ít nhiều phản ánh nguyện vọng và nỗ lực của các bên liên quan trong hành trình xuất bản: Tác giả-BBT-người phản biện. Mong muốn cơ bản, từ phía tác giả chính là câu chuyện dài của hành trình từ ý tưởng tới cái kết có hậu: xuất bản quốc tế thành công.

Tuy nhiên, xuất bản thành công mới chỉ là kết cục tốt của chặng 1: khai sinh cho tác phẩm. Chặng 2 mới thực sự quyết định thành công của tác phẩm (và tác giả): số phận của sản phẩm sau khi ra đời. Số phận ấy, giống như nhiều thứ khác trên đời, cần một số thước đo. Ngày nay, sau hàng trăm năm phát triển, thước đo ấy có thể được hình dung là các số đếm cơ bản sau.

- Số lượng xem bài (tính cả xem abstract)

- Số lượng lượt download bản đầy đủ

- Số đo Altmetric (https://www.altmetric.com)

- Số lượng trích dẫn (citations / citation count)

Trong 4 số đo này, một số người kỳ vọng Altmetric sẽ dần tranh đoạt vai trò về xác lập ảnh hưởng của tác phẩm-tác giả với xã hội rộng lớn. Tuy nhiên điều này đã không xảy ra, mặc dù Altmetric cũng được cổ vũ và nhận biết rộng rãi hơn.

Hình 4. Ví dụ về số đo Altmetric của một CBQT 


\section{Online attention}

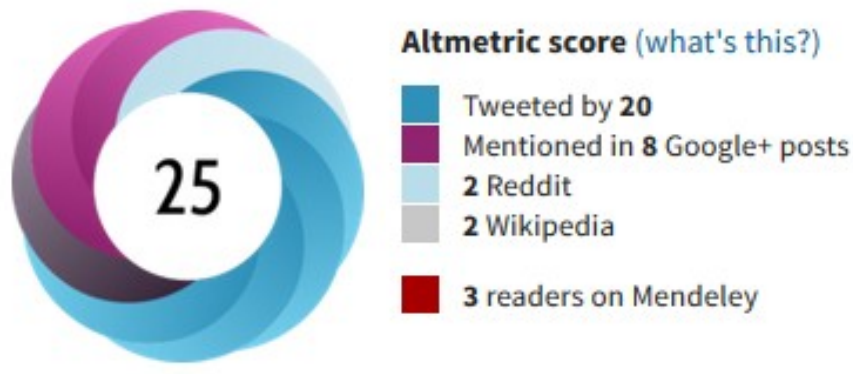

This Altmetric score means that the article is:

- in the $92^{\text {nd }}$ percentile (ranked $25,196^{\text {th }}$ ) of the 330,895 tracked articles of a

similar age in all journals

- in the $47^{\text {th }}$ percentile (ranked $33^{\text {rd }}$ ) of the 63 tracked articles of a similar age in

Nature Human Behaviour

Để có các số đo nói trên tốt thì yếu tố quyết định chính là chất lượng nghiên cứu, kèm theo đó là mức độ hấp dẫn của kết quả (được công chúng và đồng nghiệp nhiều nơi quan tâm, chú ý).

Vấn đề nảy sinh? Chất lượng đánh giá từ phía tác giả sẽ chủ quan. Chỉ có cách hữu hiệu: nộp tác phẩm vào những ấn phẩm mạnh, chất lượng cao, của các NXB uy tín và nhờ cậy vào quá trình phản biện-biên tập để tiếp tục cải thiện.

Vấn đề lại nảy sinh tiếp. Làm thế nào để biết đâu là 'ấn phẩm mạnh', 'chất lượng cao', 'NXB uy tín'? Không thể có câu trả lời hoàn hảo, nhưng nhìn chung, có thể quy ước như sau.

- NXB uy tín: Do các cá nhân, tổ chức và các tổ hợp xuất bản chuyên nghiệp lâu đời và uy tín điều hành.

- Ấn phẩm mạnh: những ấn phẩm có truyền thống xuất bản những tác phẩm nghiên cứu có ảnh hưởng rộng khắp, lâu dài và trở thành kinh điển của lĩnh vực nghiên cứu (hoặc toàn bộ thế giới khoa học).

- Chất lượng cao: nơi công bố các tác phẩm được đọc rộng rãi, được giới khoa học công nhận là địa chỉ nên thường xuyên đọc và sử dụng.

Tuy vậy, do phần lớn các tiêu chí này đều có thể không hiển nhiên với số đông (thế giới nghiên cứu là thế giới rộng lớn, nhiều ngành và đông người) do đó, người ta thường quan tâm đến một vài số đo dễ hiểu và có khả năng so sánh (ít nhất là trong cùng lĩnh vực): hệ số tác động. Hệ số này được hiểu là một kiểu loại thống kê trung bình cho số lượng trích dẫn trên một số lượng tác phẩm của ấn phẩm xuất bản qua một đơn vị thời gian. 
Nổi tiếng nhất, và cũng được quan tâm nhất là HSTĐ Journal Impact Factor (cũng còn gọi tắt là Impact Factor; JIF hay IF) được công bố định kỳ vào tháng 6 hàng năm qua báo cáo Journal Citation Reports của Clarivate Analytics (trước kia là Thomson Reuters). Clarivate là hãng phân tích dữ liệu hiện đang sở hữu ISI Web of Science, sau khi mua lại từ Thomson Reuters, do đó cũng sở hữu luôn các thương hiệu quan trọng bậc nhất về cơ sở dữ liệu (CSDL) khoa học như SCIE, SSCI, AHCI, ESCI, Current Contents, JCR, và JIF.

Cạnh tranh trực diện với JIF và CSDL ISI Web of Science ngày nay là HSTĐ CiteScore và CSDL Scopus của tập đoàn xuất bản đa quốc gia khổng lồ Elsevier. CiteScore, Scopus và thuật toán SciVal đang khiến cho Scopus trở thành CSDL ngày càng phổ biến trong xếp hạng đại học và đánh giá năng suất nghiên cứu khoa học các quốc gia.

Có thể nói, xuất bản được bài trên các tạp chí có JIF hay CiteScore cao là một mơ ước của các nhà nghiên cứu, và được coi như một 'dấu hiệu tiến bộ' trên con đường chinh phục 4 số đo đã nói khi trước. Các ấn phẩm có JIF càng cao, thì thường việc được chấp thuận đăng càng khó. (Xem ví dụ ở Hình 5)

Bây giờ, mối quan hệ xuất hiện: Các NXB uy tín thường có nhiều ấn phẩm có JIF cao. Tuy nhiên, việc đăng trên các tạp chí có JIF cao không nhất thiết dẫn đến thực tế mức độ ảnh hưởng cao của một tác phẩm cụ thể, đo qua mức độ trích dẫn, người ta thường gọi là 'article-level metric'.

Nói cho chính xác thì ấn phẩm mạnh, NXB mạnh, thường đóng vai trò bệ phóng, giúp thu hút, và tạo độ tin cậy ban đầu. Còn sức sống và ảnh hưởng thật của tác phẩm phải do giá trị, chất lượng và mức độ hấp dẫn của bản thân tác phẩm tạo nên.

Dù sao đi nữa, thì việc có thể vượt qua các trạm kiểm soát chất lượng gắt gao của các ấn phẩm mạnh, các BBT và phản biện có tính, là một dịp quý giá để kiểm tra giá trị tác phẩm, cũng như cơ hội lắng nghe để cải thiện chất lượng sản phẩm. Đây thực sự là 'cơ hội' dành riêng cho tác giả. 
Journal Data Filtered By: Selected JCR Year: 2017 Selected Editions: SCIE,SSCI Selected Category Scheme: WoS

\begin{tabular}{|c|c|c|c|c|}
\hline Rank & Full Journal Title & Total Cites & $\begin{array}{l}\text { Journal } \\
\text { Impact }\end{array}$ & $\begin{array}{c}\text { Eigenfactor } \\
\text { Score }\end{array}$ \\
\hline 1 & CA-A CANCER JOURNAL FOR CLINICIANS & 28,839 & 244.585 & 0.066030 \\
\hline 2 & NEW ENGLAND JOURNAL OF MEDICINE & 332,830 & 79.258 & 0.702000 \\
\hline 3 & LANCET & 233,269 & 53.254 & 0.435740 \\
\hline 4 & CHEMICAL REVIEWS & 174,920 & 52.613 & 0.265650 \\
\hline 5 & Nature Reviews Materials & 3,218 & 51.941 & 0.015060 \\
\hline 6 & NATURE REVIEWS DRUG DISCOVERY & 31,312 & 50.167 & 0.054410 \\
\hline 7 & JAMA-JOURNAL OF THE AMERICAN MEDICAL ASSOCIATION & 148,774 & 47.661 & 0.299960 \\
\hline 8 & Nature Energy & 5,072 & 46.859 & 0.020430 \\
\hline 9 & NATURE REVIEWS CANCER & 50,407 & 42.784 & 0.079730 \\
\hline 10 & NATURE REVIEWS IMMUNOLOGY & 39,215 & 41.982 & 0.085360 \\
\hline 11 & NATURE & 710,766 & 41.577 & 1.355810 \\
\hline 12 & NATURE REVIEWS GENETICS & 35,680 & 41.465 & 0.094300 \\
\hline 13 & SCIENCE & 645,132 & 41.058 & 1.127160 \\
\hline 14 & CHEMICAL SOCIETY REVIEWS & 125,900 & 40.182 & 0.275690 \\
\hline 15 & NATURE MATERIALS & 92,291 & 39.235 & 0.195000 \\
\hline 16 & Nature Nanotechnology & 57,369 & 37.490 & 0.170630 \\
\hline 17 & LANCET ONCOLOGY & 44,961 & 36.418 & 0.136440 \\
\hline 18 & REVIEWS OF MODERN PHYSICS & 47,289 & 36.367 & 0.054550 \\
\hline 19 & NATURE BIOTECHNOLOGY & 57,510 & 35.724 & 0.161460 \\
\hline 20 & NATURE REVIEWS MOLECULAR CELL BIOLOGY & 43,667 & 35.612 & 0.095540 \\
\hline 21 & NATURE REVIEWS NEUROSCIENCE & 40,834 & 32.635 & 0.069940 \\
\hline 22 & NATURE MEDICINE & 75,461 & 32.621 & 0.171980 \\
\hline 23 & Nature Photonics & 39,331 & 32.521 & 0.128120 \\
\hline 24 & NATURE REVIEWS MICROBIOLOGY & 26,627 & 31.851 & 0.055490 \\
\hline 25 & CELI & 230,625 & 31.398 & 0.583260 \\
\hline 26 & ADVANCES IN PHYSICS & 5,747 & 30.917 & 0.005040 \\
\hline 27 & Energy \& Environmental Science & 71,920 & 30.067 & 0.180320 \\
\hline 28 & World Psychiatry & 4,055 & 30.000 & 0.010540 \\
\hline 28 & World Psychiatry & 4,055 & 30.000 & 0.010540 \\
\hline 30 & LANCET NEUROLOGY & 28,671 & 27.138 & 0.069040 \\
\hline 31 & NATURE GENETICS & 93,639 & 27.125 & 0.234110 \\
\hline 32 & NATURE METHODS & 54,686 & 26.919 & 0.243170 \\
\hline 33 & PSYCHOLOGICAL INQUIRY & 4,063 & 26.364 & 0.003220 \\
\hline 34 & JOURNAL OF CLINICAL ONCOLOGY & 156,474 & 26.303 & 0.285130 \\
\hline
\end{tabular}

Hình 5. Một số ấn phẩm có JIF 2017 cao nhất (Journal Citation Reports ${ }^{\mathrm{TM}}$ 2018)

Kirwan (scholar.google.com/citations?user=57pKMKwAAAAI) của University of Bristol, chia sẻ trên Nature về sự nghiệp của bản thân rằng đối với các công việc đã được tiến hành thì con số thành công chỉ là $38 \% .^{3}$ Điều đó có nghĩa là ngay cả đối với các nhà khoa học hạng nhất, nhận được quyết định "Accept" cũng có ý nghĩa rất đáng kể. Vì vậy, để bước vào giai đoạn cọ xát, cải thiện, sửa đổi, tranh đấu lý lẽ, cho tới khi được chấp thuận xuất bản, có một bản thảo tốt là một bước đệm gọn gàng và tất cả những gì một tác giả mong muốn (Kirwan, 2017).

Hộp 1. Tình hình chung xuất bản KHXH\&NV Việt Nam 2008-2018

Dữ liệu thống kê của NVSS (https://sshpa.com):

${ }^{3}$ xem thêm: https://sc.sshpa.com/post/4153.

CC2018 Vuong Q.H. — email: qvuong.ulb@gmail.com — https://sc.sshpa.com 
- Nhà khoa học: 2404 (Việt Nam: 1065)

- Bài viết: 1935

- Cơ quan: 1060 (Việt Nam: 385)

- Tạp chí: 1019

\section{Viết nghiên cứu}

Vậy thì, thực sự viết nghiên cứu khoa học là gì?

Câu hỏi tưởng chừng rất đơn giản này, hóa ra lại không hề đơn giản. Sau khi thảo luận với nhiều người trong một số ngành khác nhau, tôi tạm rút ra cách định nghĩa đơn giản như sau:

- Một quan điểm có ích về nghiên cứu: Nghiên cứu là quan sát những gì người khác cũng quan sát, nhưng nghĩ điều mà (hy vọng rằng) chỉ có mình nghĩ đến.

- Một quan điểm về nghề viết có thể ứng dụng được: Viết là nghĩ trên giấy.

Do đó, có thể hiểu công việc chứa nội dung chính:

Viết nghiên cứu là quá trình đặt những suy nghĩ riêng nhất của mình về đối tượng quan sát lên trên giấy. Quá trình này được thực hiện tuân thủ các chuẩn mực phân tích và trình bày khoa học.

Mỗi người có thể sẽ có cách định nghĩa riêng cho mình. Tựu chung, lợi ích của việc này là hình thành nên mức độ quan tâm sâu hơn, và xuất phát từ suy nghĩ của bản thân. Chính đó đã đại diện cho một bước tiến thú vị về nhận thức nghề nghiệp.

\subsection{Bối cảnh và sự cần thiết của việc viết công bố quốc tế}

Bối cảnh ngành nghề nghiên cứu quốc tế và câu chuyện "publish or perish"—dù được nhắc đến với ý nghĩa tiêu cực, tích cực, hay trung tính-trong giới học thuật hiện nay góp phần khiến công bố khoa học trở nên sôi động. Sự hình thành, phát triển của khoa học quốc tế và xuất bản quốc tế từ những tạp chí đầu tiên năm 1665 tại Anh và Pháp (Banks, 2018) đã tạo nên những quy chuẩn trong khoa học mà trong dòng chảy toàn cầu hóa hiện nay, không một nước nào có thể đứng ngoài cuộc. Việt Nam cũng hòa chung vào dòng chảy đó, với sự ra đời của Quỹ phát triển khoa học và công nghệ quốc gia (NAFOSTED) vào năm 2008 với những chuẩn mực quốc tế tường minh và cụ thể, đã góp phần tạo nên sinh hoạt khoa học sôi nổi và đa dạng hơn rất nhiều. ${ }^{4}$

\section{Bối cảnh quốc tế:}

${ }^{4}$ Tham khảo: https://sc.sshpa.com/post/1098. 
Công bố khoa học đã không còn là chuyện xa lạ. Sự ảnh hưởng và uy tín học thuật của các nhà nghiên cứu lớn luôn được đánh giá qua năng suất cũng như chất lượng nghiên cứu. Ngay từ trong những năm trong học, học sinh quốc tế đã được tiếp xúc với các tiêu chuẩn và kiến thức học thuật đỉnh cao. Ví dụ tại Mỹ, cuộc thi Science Talent Search cho học sinh trung học bắt đầu từ năm 1942 và nhiều người thắng cuộc đã tiếp tục đạt các giải thưởng lớn khác như Nobel hay Fields sau này. Hay đối với bậc học tiến sĩ trên thế giới, yêu cầu phổ biến ngày nay bên cạnh luận văn là có 2 3 nghiên cứu được xuất bản trước khi tốt nghiệp.

Vì vậy, cạnh tranh trong nghề nghiên cứu đang gia tăng với số lượng Ph.D. đào tạo tăng vọt ở hầu hết tất cả các ngành: dưới $10 \%$ tốt nghiệp có thể "tìm được việc trong mo" trong môi trường học thuật khắc nghiệt hiện nay. Để có thể có một công việc trong ngành học thuật, việc không có đủ số lượng công bố hoặc thiếu các công bố chất lượng tốt sẽ làm giảm cơ hội thăng tiến hay uy tín nghề nghiệp, giảm cơ hội để có nguồn thu từ tài trợ khoa học, hay thậm chí là mất cả "biên chế".

Cuối cùng, công bố khoa học không chỉ là vấn đề cá nhân mà còn ảnh hưởng đến uy tín của tập thể. Trường kém sản lượng và chất lượng công bố sẽ không có khả năng cải thiện uy tín ngành, không thu hút được sinh viên giỏi, không thu hút được giáo sư giỏi, không vào các bảng xếp hạng quan trọng (THE, QS, Shanghai Jiao Tong, v.v..), khó có các ứng viên vào các danh sách đề cử cho các giải thưởng khoa học uy tín, suy yếu nội lực thu hút sinh viên quốc tế.

\section{Bối cảnh Việt Nam:}

Việt Nam hiện nay đang có những chuyển động mạnh mẽ hướng đến công bố quốc tế (CBQT), đặc biệt là KHXH\&NV. Đối với các nhà nghiên cứu trong nước, không có CBQT sẽ không có các hồ sơ khoa học hợp lệ và đạt chuẩn để đấu thầu các đề tài khoa học cấp quốc gia, thậm chí cấp bộ, thậm chí ngay cả cấp nhà trường. Các nguồn tài trợ chủ lực ('research grant') sẽ chuyển mạnh tiêu chuẩn đánh giá sang xem xét năng lực $\mathrm{CBQT}$, và tiêu chí thẩm định thành công đề tài sang xem xét số lượng và phẩm cấp của thành phẩm xuất bản đã thực hiện trong suốt chu kỳ dự án. ${ }^{5}$

CBQT cũng trở thành tiêu chuẩn để đánh giá uy tín khoa học của một nhà khoa học. Thiếu CBQT sẽ cản trở con đường hợp tác nghiên cứu, hợp tác ứng dụng do suy giảm uy tín cá nhân của nhà giáo/nhà khoa học.

Xét trong ngành học thuật nói chung, việc phân tách giữa nghiên cứu và giảng dạy sư phạm đang được xóa bỏ. Ví dụ, các giáo sư hướng dẫn muốn tiếp tục bắt buộc phải có CBQT đạt chuẩn. Hay để tốt nghiệp quá trình học tập bậc tiến sỹ, bắt buộc phải có công bố đạt chuẩn.

\footnotetext{
5 Tôi cố gắng sử dụng tối đa các tài liệu đã xuất bản của chính mình, để gia tăng độ tin cậy trao đổi về
} trải nghiệm cá nhân (thường được gọi là 'first-hand experience'). 
Không dừng lại ở đó, các chuẩn nói trên sẽ tiếp tục khắt khe thêm theo thời gian, ví dụ với các GS hướng dẫn, chắc chắn sẽ tăng lên mức "sản lượng sàn", ví dụ, không được dưới 5 bài; và/hoặc thêm mức "chất lượng sàn", ví dụ: phải có bài ở vị trí tác giả thứ nhất hoặc tác giả đầu mối “corresponding”), trên các tạp chí Q2 trở lên, v.v..

Các giáo sư hướng dẫn cũng không còn các giới hạn về tư liệu trong thời đại Internet, vì thế nếu chỉ dựa vào các chuẩn đã cũ, bài giảng và quá trình hướng dẫn sinh viên và học viên từ bậc $\mathrm{S} Đ H$ sẽ bị vào lối mòn, khó có khả năng tiếp cận tri thức mới; đó là chưa nói đến loại tri thức gốc ("authentic") của người đứng trên bục giảng. Vì vậy, công việc nghiên cứu chính là một cách để cập nhật với tri thức mới.

Hướng dẫn $\mathrm{S} Đ H$ cũng không chỉ gói gọn trong giảng dạy mà nó phải có mục tiêu cụ thể hướng đến các hoạt động khoa học. Vì thế, các giáo sư hướng dẫn cần có khả năng dẫn dắt các nhóm nghiên trẻ hơn để dần tạo ra truyền thống và tính bền vững của hoạt động nghiên cứu.

Hiện nay, liên tiếp xuất hiện các vấn đề nóng bỏng trong chất lượng khoa học không chỉ của học viên, mà cả các giảng viên, tác động mạnh đến uy tín của ngành giáo dục, thậm chí gây tổn thất tới nghề nghiên cứu khoa học - một nghề được trao sứ mệnh cao quý là mở đường cho ánh sáng tri thức đến với xã hội.

Hộp 2. Trả lời câu hỏi "CBQT cần để làm gì?"

CT1. Để trả lại sự tôn trọng và uy tín nghề nghiệp cho công tác NCKH.

CT2. Nhằm cải thiện vị trí, năng lực chuyên gia của nhà giáo/nhà khoa học.

CT3. Cải thiện khả năng tiếp cận các nguồn tài trợ khoa học dựa trên năng lực.

CT4. Bổ sung tri thức "gốc" phục vụ giảng dạy và hợp tác NCKH.

CT5. Đủ năng lực đào tạo các thế hệ chuyên gia trong tương lai.

CT6. Gây dựng thương hiệu quốc tế về nghiên cứu.

CT7. Gây dựng niềm tin với công chúng và giới chức chính sách.

Vậy công bố bao nhiêu bài nghiên cứu chất lượng thì có thể được xem là đã "khởi nghiệp thành công" nghề nghiên cứu? Câu trả lời: "Quy tắc Krugman mở rộng": 3. Tại sao 3?

1. $\rightarrow$ Hello World!

2. $\rightarrow$ Tôi vẫn tiếp tục, không phải do ăn may!

3. $\rightarrow$ Tôi còn ở đây lâu!

\subsection{Xác định nội dung nghiên cứu và những đóng góp của nghiên cứu}

Bản chất của NCKH là trả lời một số câu hỏi quan trọng. Theo quy tắc chung của tiếp cận tri thức, việc trả lời đó được tiến hành qua việc trả lời một số lượng lớn hơn các câu hỏi nhỏ hơn, đỡ khó hơn, và liên quan qua một logic tạm gọi là "hợp lý cực đại". 
Chúng ta bắt đầu với ý niệm chung nhất về "nội dung nghiên cứu", một khái niệm dễ nói nhưng không dễ hiểu, và nhiều khi tù mù, nằm ở khoảng mờ, cần dùng đến rất nhiều kinh nghiệm và được bố trí theo cách đôi khi khá là "nghệ sĩ" (tham khảo: Vuong \& Napier, 2017).

\section{Nôi dung nghiên cứu là gì?}

Nội dung nghiên cứu là một cụm từ "gộp" bao hàm những khái niệm thành phần, rất quan trọng như sau:

- $\quad$ Bối cảnh ra đời nghiên cứu là gì? (Quan sát hay câu chuyện hay nghiên cứu nào trước đó dẫn tới ý tưởng này?) - Tương ứng với phần "Introduction" trong bài.

- Xưa nay hướng nghiên cứu này có gì hay, đáng quan tâm, hữu ích, và còn yếu/thiếu gì? - hay "Literature Review".

- Bạn có suy nghĩ, quan sát đáng kể, dữ liệu và/hoặc kết luận nào mà giới khoa học cần phải biết đến (cũng là chứng minh raison d'être của bản thảo/công bố) - Phần "Materials" hoặc "Data".

- Một vài thông điệp quan trọng nhất làm sáng tỏ khúc mắc, đính chính hiểu biết sai (kể cả về phương pháp luận) - "Results" và/hoặc "Discussion".

- Ai sẽ cần đến hiểu biết này, và sử dụng thế nào? - Phần "Implication".

- Liệu hướng này còn đi đến đâu nữa? - Mục "Conclusion".

Có thể thấy, toàn bộ các khái niệm thành phần của nội dung nghiên cứu tương ứng với một phần quen thuộc trong một bài nghiên cứu cụ thể. Trả lời được các câu hỏi này, nghĩa là ta đã có một dàn ý sơ lược.

*Lưu ý: Trong nhiều tình huống cuộc sống thật, khi giao tiếp với các hãng tư vấn, họ cũng thường sử dụng từ "nghiên cứu" ("research") để chỉ một báo cáo kinh doanh, kiểu như "market research", hay "investment research", nhưng chúng không thuộc phạm trù nghiên cứu chúng ta đang bàn đến, "academic research". Thực chất chúng là các báo cáo đánh giá.

\section{Xác định nội dung là xác định cái gì?}

Việc xác định nội dung thực chất là tìm ra cho mình câu trả lời, trước tiên và trên hết, của chính bản thân mình về những gì muốn làm, muốn thấy xuất hiện trong bản thảo, và muốn thuyết phục độc giả, đồng nghiệp và các ban biên tập rằng: "Hàng hóa tôi làm ra nên được bầy trên kệ".

Như vậy, xác định nội dung được chuyển hóa từ phần trình bày phía trên về nội dung nghiên cứu, thành các hoạt động cụ thể, nhằm biết được chính xác cái gì sẽ hoàn thành và gửi đến độc giả (nên xem công chúng, đồng nghiệp, các cây bút phản biện, các ban biên tập, sếp, vợ/chồng con cái... đều như độc giả cần thuyết phục). 
- Tôi sẽ rà soát bao nhiêu tài liệu? Tôi sẽ có xu hướng tìm ra điểm nào còn khuyết thiếu/yếu kém trong tàng thư khoa học để xắn tay vào làm? Trong những thứ tôi rà soát được, liệu có những điều gì đáng chú nhất, và chúng nên được sắp thứ tự ưu tiên thế nào thì tốt cho nhận thức? Có cách gì sáng tạo và thông minh hơn để rà soát lý thuyết tổng quan hay không? Bài nghiên cứu "On the sustainability of co-authoring behaviors in Vietnamese social sciences: A preliminary analysis of network data" trên tạp chí Sustainability năm 2017 đã rà soát 80 tài liệu về chủ đề bền vững nói chung và cách các nhà khoa học áp dụng khái niệm bền vững trong các bối cảnh khác nhau (Ho, Nguyen, Vuong \& Vuong, 2017).

- Data của tôi có đáng kể không, đáng tin cậy không, và có thể chứng minh tầm quan trọng của chúng không? Có cách trình bày data nào hợp lý, và nếu sáng tạo thì càng tốt, để cho thấy khả năng "kể chuyện" của data? Ví dụ bài nghiên cứu về tam giáo đồng nguyên đã "dữ liệu hóa" các câu chuyện cổ tích quen thuộc và nhìn nhận chúng dưới lăng kính thống kê (Vuong et al., 2018).

- Tôi có suy nghĩ gì sáng tạo, bất ngờ, hay sâu xa hơn (so với những nghiên cứu đã từng đọc được) mà không nên bỏ qua, cần được ghi lại? Tôi tình cờ phát hiện thấy vấn đề về giá của khoa học, đặc biệt là trong nền kinh tế như Việt Nam mà chưa có nhà khoa học nào đề cập đến? Những bệ phóng hẹp nhưng mạnh mẽ này hoàn toàn có thể thuyết phục được một tạp chí trong hệ thống xuất bản hạng nhất như Nature Research chấp thuận (ví dụ: Vuong, 2018).

- Có một (vài) quan sát nào (có bằng chứng là tốt nhất) khiến một chuyên gia trong ngành khi đang đọc phải dừng lại ngẫm nghĩ không? Sau nhiều lần trả lời phản biện, những kinh nghiệm đó đã được phát triển thành một bài quan điểm (viewpoint) trên tạp chí European Science Editing (Vuong, 2017a).

- Những chỗ tắc nghẽn, thách thức, khó khăn tưởng chừng như khó vượt qua nhất, lại có thể là cơ hội tốt nhất để dẫn đến một tác phẩm được đánh giá cao (xem: Vuong \& Napier, 2017)

- Những câu trả lời có giúp mang đến một vài hiểu biết gì khá thú vị, mới và có ích? Làm sao để những câu trả lời đó được đặt vào trong một khuôn khổ hợp lý, cân đối, ngôn ngữ trong sáng và dễ hiểu, không chỉ với chuyên gia/đồng nghiệp mà cả những người có nền tảng kiến thức vừa phải (vừa đủ để đọc tài liệu kỹ thuật).

- Xác định khả năng ảnh hưởng của kết quả, và chỉ ra một vài xu hướng có thể mở rộng việc tìm tòi hiểu biết mới xung quanh kết quả/kết luận được trình bày trong bài. Có thể lấy điểm tựa đầu tiên là dự báo cho chính hành vi nghiên cứu của mình (với giả định rằng mình có thời gian, nguyện vọng và dữ liệu để tiếp tục khai thác). Ví dụ, nghiên cứu trên tạp chí Societies đưa ra những kết quả ban đầu sau khi phân tích ảnh hưởng của các yếu tố xã hội và nhân khẩu học đến năng suất khoa học của các nhà nghiên cứu KHXH Việt Nam. Các kết quả ban đầu đã đưa ra những gợi ý về các chính sách khoa học (Vuong et al., 2018). Đối với dự án, thì kết quả và cả thiếu sót của bài đó đã đặt ra các hướng phát triển cho việc nghiên cứu và mở rộng dữ liệu. 


\section{Làm thế nào để xác định hợp lý được nội dung?}

Chắc chắn là có nhiều cách khác nhau trả lời câu hỏi này. Cách sau đây chỉ là một, và xuất phát từ quan sát cộng đồng, kèm theo trải nghiệm bản thân.

Trước hết, suy ngẫm đủ lâu và đủ kỹ về ý định và câu hỏi nghiên cứu sơ khởi của bản thân. Đây là công đoạn không thể vội vã. Đi tắt khâu này sẽ dẫn đến "sloppy science", "shoddy science" và thậm chí "pseudo-science". Câu hỏi đặt ra là vậy làm sao để biết mình đã suy ngẫm đủ kỹ? Câu trả lời chỉ có thể tìm thấy khi chúng ta bắt đầu làm việc: trao đổi với đồng nghiệp, rà soát kĩ các lý thuyết, viết nháp những dòng đầu tiên ... Thông qua những công việc đó, chúng ta sẽ có được sự phản ánh tương đối về suy nghĩ của mình và có thể đưa ra những đánh giá tương đối. Nên lưu ý rằng thời gian có thể kéo dài đến hàng năm. Ví dụ George Orwell mất 6 năm ròng để tìm ra cách viết cho tác phẩm Animal Farm (1945); một tác phẩm ngắn đã đưa ông trở thành đại văn hào của nhân loại.

Tiếp theo, cần kiên nhẫn đọc các nghiên cứu liên quan, tập trung vào những tài liệu có giá trị cao.

Vây làm sao để biết một tài liệu có giá trị cao? Số lượng trích dẫn, uy tín của tác giả, gợi ý của đồng nghiệp, uy tín của tạp chí ... các thông tin này là hữu ích để đánh giá sơ bộ. Đi sâu hơn, chúng ta phải tìm được điểm ấn tượng của tài liệu: dữ liệu, phương pháp có gì đặc biệt; phần tổng quan tình hình nghiên cứu có gì lí thú không, thảo luận có điểm gì đáng chú ý ...

Cũng ở đây, lại có câu hỏi:

Vây làm sao để biết đoc bao nhiêu tài liêu là tương đối đủ? Điều này phụ thuộc vào từng ngành và bối cảnh cụ thể. Ví dụ nghiên cứu về kinh tế tại Việt Nam sẽ có số lượng tài liệu nhiều hơn so với nghiên cứu về mỹ thuật tại Việt Nam.

Có thể tạm rút ra rằng, đọc là các tài liệu hữu hiệu nhất để bổ sung nền tảng. Nếu bạn không biết bắt đầu từ đâu và nên đọc như thế nào, các bạn hãy bắt đầu với một tài liệu bất kì và dựa trên phần rà soát tổng quan và trích dẫn của tài liệu đó để truy tìm các tài liệu khác. (Quý vị quan tâm chi tiết kỹ hơn xin vui lòng tham khảo thông tin bổ sung tại địa chỉ: https://sc.sshpa.com/post/1038.)

Thứ $b a$, rút ra vài câu trả lời rất quan trọng cho câu hỏi trong Hộp 3.

Hộp 3. Câu cần hỏi

- V Với kiến thức đã thấy trong kho tàng, cộng với vấn đề cuộc sống, mối quan tâm nghiên cứu đương thời, chỗ nào là điểm "cảm thấy" có thể đóng góp 


được, và hoàn thành hiệu quả?
- Phạm vi của vấn đề, câu hỏi mình muốn xử lý rộng tới đâu (bao nhiêu khía
cạnh liên quan) và sâu tới đâu (sử dụng kỹ thuật gì)?
- Những câu hỏi khó nhất về giá trị của suy nghĩ, giá trị của dữ liệu và giá trị
(có thể có) của kết quả là gì? Ta có thể vượt qua được không, nếu bị phán
biện "khoét" đúng vào những chỗ khuyết nhược mong manh, dễ vỡ đó?
- Hạn chế lớn nhất về suy nghĩ, quan sát và dữ liệu đang sử dụng cho công
việc nghiên cứu này là gì?

Thứ tư, dành thời gian và công sức chuẩn bị dữ liệu thật tốt; đồng thời cũng không nên bị ám ảnh rằng dữ liệu tốt là có nhiều dữ liệu, hay bộ dữ liệu có rất nhiều đặc tính thống kê. Một phần rất quan trọng của xác định phạm vi nội dung nằm ở data. Lấy ví dụ căn bản, ta không thể nghiên cứu vấn đề toàn cầu mà chỉ có duy nhất dữ liệu của Việt Nam được. Đồng thời xác định khả năng cấu trúc data đó. Có những loại data có khả năng được cấu trúc hóa để trở nên linh hoạt hơn trong quá trình phân tích. Nhưng có những loại thì rất cứng nhắc, chỉ cho phép tiến hành một số phép tính toán thống kê đơn giản.

Nếu không phải là loại data có thể áp dụng các phương pháp thống kê mà các phương pháp định tính phân tích sâu, phân tích nội dung thì cần phải có câu hỏi nghiên cứu chắc chắn và nắm vững khung lý thuyết. Data cũng cần phải đảm bảo phù hợp và đầy đủ với phạm vi nghiên cứu.

Một đẳng thức ngày nay thường gặp: Science = Data.

\section{Làm thế nào để tự đánh giá về kết quả nghiên cứu?}

Gợi ý 1 : Đọc 3 lần bản thảo cuối cùng, xem đến hết lần 3 , bản thân mình có còn thấy ý nghĩa hay hứng thú nữa không. Sức hấp dẫn còn lại sau 3 lần đọc (và nhiều tháng chiến đấu trên bản thảo) mà đáng kể thì rất đáng mừng. Đằng sau sức hấp dẫn đó là kết quả và đóng góp khả dĩ.

Gợi ý 2: Đối chiếu với các kết quả đã công bố, gần và liên quan trực tiếp tới kết quả bản thân, để kiểm tra sức thuyết phục và so sánh chất lượng lập luận. Đặc biệt chú ý tới các tác giả đồng hạng.

Gợi ý 3: So sánh mức độ tương thích của kết quả với các nghiên cứu đã công bố, trên các tạp chí chất lượng tốt, cùng loại (nếu có), tìm được nghiên cứu có cùng cấu trúc dữ liệu thì càng tốt. Có hai khả năng xảy ra: 
- Tương thích với các kết quả gần đây, nổi trội, và tương thích luôn với lý thuyết nền, thì yên tâm;

- Không tương thích một chút nào với cả kết quả gần, liên quan, lẫn lý thuyết, thì cần tiếp tục quan sát. Nếu kiểm tra lập luận chuẩn xác, logic dữ liệu tốt, cách xử lý thống kê tốt, và việc rút ra đánh giá hợp lý thì thật đáng chúc mừng: Chúng ta đang đứng trước cơ hội đóng vai "black sheep".

Gợi ý 4: Bắt tay vào viết nghiên cứu nghiêm chỉnh là một cách đánh giá rất "hiệu quả". Để viết khởi đầu và kết thúc viết nghiên cứu, thuận lợi, nên theo quá trình 4 bước - dễ thực hành, dễ nhớ - của Angel Borja (2015), viết trên mục cố vấn khoa học của Elsevier:

- Dành nhiều thời gian suy nghĩ về chủ đề định trình bày. Đừng vội triển khai ngay những suy nghĩ đầu tiên. Hãy nghĩ nhiều ngày, thậm chí nhiều tuần. Nghĩ tới, nghĩ lui, lật đi lật lại vấn đề cho thật ngấm.

- Hãy dùng suy nghĩ và dữ liệu (nếu có) để chuẩn bị các hình ảnh, sơ đồ, đồ thị, và các bảng dữ liệu. Chúng là những nguyên liệu vô cùng quan trọng.

- Thế rồi bắt tay viết khẩn trương, viết nhanh nhất có thể. Viết như thể đọc lên thành lời những suy nghĩ của mình. Ghi xuống mọi thứ có thể nghĩ, dù có thể lộn xộn ban đầu, có thể sai ngữ pháp, chính tả, bất chấp cả phong cách chưa chuẩn và từ ngữ chưa mực thước.

- Q Quay vào việc sửa lỗi, viết lại các đoạn văn, chỉ khi nào toàn thể các đoạn văn và các ý đã nằm trên giấy.

*Lưu ý đáng giá: Nếu có vài tác giả cùng tham gia dự án, đừng chia việc soạn bản thảo cho nhiều người. Hãy chủ động hoàn thành bản đầu tiên, một tay mình xử lý toàn thể. Các đồng tác giả có đóng góp hiệu quả nhất chỉ khi bản thảo đã xong, và họ bắt tay vào chỉnh sửa, góp ý, bổ sung thêm đoạn văn mới, ý tưởng riêng. Khi mời đồng tác giả tham gia, hãy yêu cầu sử dụng tính năng 'track-change' để biết ai đã sửa gì, và đảm bảo tính chỉnh thể của văn bản khoa học.

\subsection{Cấu trúc chuẩn của một nghiên cứu quốc tế}

Trước tiên, bài nghiên cứu nào cũng có tiêu đề. Theo gợi ý James Hartley (2018) Keele University - thì có 3 loại cấu trúc và 13 kiểu viết tiêu đề. Tiêu đề rất quan trọng, vì nó là cửa ngõ của nội dung, và phần nào nói lên tổng quan ý tưởng của nghiên cứu. Đôi khi tiêu đề là hướng nội dung, lúc khác là câu trả mạch lạc, cũng có khi là câu hỏi. Ví dụ, "Serendipity as a strategic advantage?" (Vuong \& Napier, 2013) hoặc "Are student flows a significant channel of R\&D spillovers from the north to the south?" (Le, 2010) là những dạng tiêu đề câu hỏi. "Survey data on Vietnamese propensity to attend periodic general health examinations" (Vuong, 2017c) là dạng tiêu đề nói rõ nội dung của bài còn "Exploring Vietnamese co-authorship patterns in social sciences with basic network measures of 2008-2017 Scopus data" (Ho et al., 2017) là dạng tiêu đề nêu lên hướng nội dung. ${ }^{6}$

${ }^{6}$ Tham khảo: https://sc.sshpa.com/post/1031. 


\section{Có cấu trúc "one size fits all" không?}

Cấu trúc một bài báo quốc tế phụ thuộc vào mấy yếu tố sau đây:

- Loai bài đinh viết ("original research", "review article", "research letter", "commentary", "book review", "book chapter", "essay", "short communications", "data / method research", v.v..). Ví dụ: Book review có thể tham khảo Chau B. Vu (2017) hoặc Truong Van Dao (2013); Book chapter có thể xem Pham Quang Minh (2015), Giang Thanh Long (2012) hoặc Bui Thanh Huong và Le Tuan Anh (2017). Nếu quan tâm kỹ hơn đến thể loại nhằm xác định phù hợp nhu cầu cá nhân, xin vui long tham khảo thêm bài giới thiệu về 6 loại ấn phẩm và 8 loại bài nghiên cứu, tại địa chỉ https://sc.sshpa.com/post/1070.

- Loai vât liệu có để xây dưng nên kết quả (mức độ đậm đặc của data, mức độ lý thuyết hóa, có phải khai triển mô hình thống kê mới, có phải chứng minh một vài định đề hay bổ đề nào liên quan, có sử dụng các hình ảnh nghiên cứu nguyên gốc...). Ví dụ Nghiên cứu "Do minimum wages affect firms' labor and capital? Evidence from Vietnam" (Nguyen, 2017) thì lấy vật liệu từ Tổng cục thống kê và các phương pháp thống kê để tính toán kết quả. "Nostalgia for the New Oldness: Vietnamese Television Dramas and National Belonging" (Giang, 2014) thì áp dụng khung lý thuyết của Foucault và dữ liệu nội dung từ hai bộ phim truyền hình.

- Tâp quán của ngành (giáo dục khác với y, kinh tế, hay vật lý). Đôi khi khác biệt này khá lớn, nhất là về phương diện trình bày. Chủ yếu là do nguyên nhân phương pháp luận nghiên cứu và kiểu kết quả cần giới thiệu. Tuy nhiên, qua thời gian dài, sự khác biệt dần dần tạo thành chuẩn. Ví dụ, cấu trúc bài ngành y xã hội hầu như tương đương nhau, và thậm chí yêu cầu cả Abstract cũng phản ánh cấu trúc đó ("IMRaD”).

Về cơ bản, không nên cố tạo ra một kiểu mẫu "one size fits all" cho các nghiên cứu của mình. Hãy để tình huống quyết định cách trình bày. Điều đáng chú ý là việc cần tôn trọng các nguyên lý căn bản của công việc biểu đạt kết quả khoa học. Chỉ có điều đó là đáng quan tâm nhất.

\section{Độ dài và văn phong?}

"A good speech should be like a woman's skirt; long enough to cover the subject and short enough to create interest."

Một số thông tin dưới đây có thể có ích trong quá trình cân nhắc để lựa chọn phong cách phù hợp cho nghiên cứu:

- Câu văn trực tiếp đi thẳng vào chủ đề và ngắn luôn có lợi.

${ }^{7}$ https://www.goodreads.com/quotes/421900-a-good-speech-should-be-like-a-woman-s-skirt-long 
- Các câu văn dài không làm cho bài nghiên cứu trông có điệu bộ "chuyên nghiệp" hơn; thực tế, chúng chỉ gây ra sự bối rối và hiểu nhầm.

- Độ dài trung bình của câu tiếng Anh trong các nghiên cứu xuất bản ngày nay nằm trong khoảng 12-17 từ.

- $\quad$ Hãy nghĩ thế này: Độc giả đọc một câu trong một hơi thở. Câu văn dài cũng tương tự như bóp cổ người đọc! (Xem Hình 6)

Ngày nay các chuẩn mức ngày càng xác lập, do đó, việc tuân theo chuẩn mực chung cũng là một phương thức giúp tiết kiệm thời gian, và giảm bớt bất trắc trong việc chuẩn bị bản thảo nghiên cứu, cũng như trong cả công tác biên tập, thậm chí cả bình duyệt.

Hình 6. Câu văn 'bóp cổ’ độc giả tắc thở

... Conversely, applying M-AMBI the ex-
plained va fiability reaches until $43.4 \%$,
for linear regression, and $53.8 \%$ for log-
arithmic regression, and the highest ex-
plained variability was found in high
and low mesohaline and polyhaline
areas ( $53-63 \%$ ), whilst the lowest ex-
plained variability was in the oligoha-
line area (6\%), being the mismatch in
the comparison of both methods in
terms of degraded-undegraded equiva-
lences was of $16.4 \%$ of the cases in
M-AMBI, and $12.7 \%$ in B-IBI, with a high
spatial level of agreement. ...

(Nguồn: Nature.com)

Một vài gợi ý về cách viết đoạn văn:

- C Câu mở đầu đoạn nên là câu chủ đề.

- C Câu chủ đề nên dùng lời văn của bản thân, không nên dùng trích dẫn của người khác.

- Trích dẫn ở câu mở đầu có thể làm suy yếu ý kiến của nhà nghiên cứu, vì thế trích dẫn nên được dùng ở các câu sau để thêm sức mạnh cho luận điểm được nêu.

- C Câu kết đoạn để tổng kết lại luận điểm và ý kiến củng cố nó ở trong đoạn văn.

- Cách kiểm tra một bài đơn giản là đọc tất cả các câu mở đầu cùng nhau như là một đoạn văn. Nếu đoạn văn đó đầy đủ ý của bài và dễ hiểu thì có thể nói đấy là một bài văn tương đối tốt. 
Lưu ý về trình bày "References" / "Bibliography":

- Q Quy định của tạp chí nơi gửi đăng luôn rõ ràng. Tuân thủ là điểm cộng.

- M Mặc dù việc định dạng tổng thể bài nghiên cứu luôn xảy ra trước khi đăng (trong thời kỳ paper-in-press, proofing), nhưng có những tạp chí trả lại bài (không phải từ chối, mà để hoàn thành theo tiêu chuẩn tối thiểu) gọi là "unsubmit" các bản thảo không tuân thủ yêu cầu trích dẫn.

- $\quad$ Nói chung, người đọc (biên tập hay người bình duyệt bài) đều thích các bài được trình bày sạch sẽ, nhất quán về chuẩn mực trình bày từ đầu tới cuối. Do đó, trình bày tài liệu tham khảo chu đáo có tác dụng tốt.

\section{Các qui tắc, chuẩn mực đạo đức quốc tế}

Quy tắc chung có thể tham khảo ủy ban rất quen thuộc "COPE". Những quy định cụ thể của ủy ban công bố ở đây: https://publicationethics.org/

Chuẩn mực về tư cách cần có cho công việc:

a) "Không cầm nhầm": Vay mượn ý tưởng, dữ liệu thì phải công bố rõ ràng, trích dẫn đàng hoàng;

b) "Không phóng đại": Có sao nói vậy, nói vống kết quả hay tự ca ngợi giá trị nghiên cứu là việc tuyệt đối nên tránh;

c) "Không quanh co với nhược điểm": Chắc chắn tồn tại nhược điểm, như vậy việc chủ động xác định chúng, và chỉ ra rõ ràng không phải là điểm trừ, mà là điểm cộng.

\subsection{Chuẩn mực của ấn phẩm / của ngành nghề}

Một số yếu tố làm nên khung cảnh khá bao quát của chuẩn mực đạo đức ngành nghề / ấn phẩm nói chung:

- Nhận thức về "misconduct", và hậu quả kèm theo

- $\quad$ Tính tổn thương của bên liên quan

- $\quad$ Xung đột lợi ích

- Quyền tác giả và người đóng góp

- Bảo hộ tài sản trí tuệ

- $\quad$ Khiếu nại và phúc tra

- $\quad$ Dữ liệu và điều kiện tái lập kết quả

- $\quad$ Đạo đức liên quan tới quá trình bình duyệt

- Hiệu chỉnh sau công bố, "correction" "corrigendum" "errata"

\subsection{Chuẩn mực của các nhóm "elite"}

Đó là nhóm những ấn phẩm đủ mạnh để tự họ đặt ra chuẩn riêng, cũng có thể phản ánh viễn kiến trước phần đông thế giới: 
- Q Quy định chuẩn mực kỹ thuật không có dấu hiệu vi phạm (ví dụ ảnh gốc của nghiên cứu)

- $\quad$ Công bố dữ liệu mở + computer code (Gerwin, 2016 ; Vuong, 2017b)

- $\quad$ "Post-publication review" và chuẩn mực rút bài (retraction note)

- Nhóm « elite » quen thuộc : Nature Research journals, Science journals, PNAS, CellPress journals, the Lancet Journal, New England Journal of Medicine, JAMA, v.v.. và một số lượng nhỏ các tạp chí thuộc Nature Index.

Bên lề, có thể tham khảo thông tin về một vài trường hợp vi phạm, sơ suất, và hậu quả tiêu cực, xem Hộp 4.

Hộp 4. Một số vụ việc tiêu biểu được quan tâm

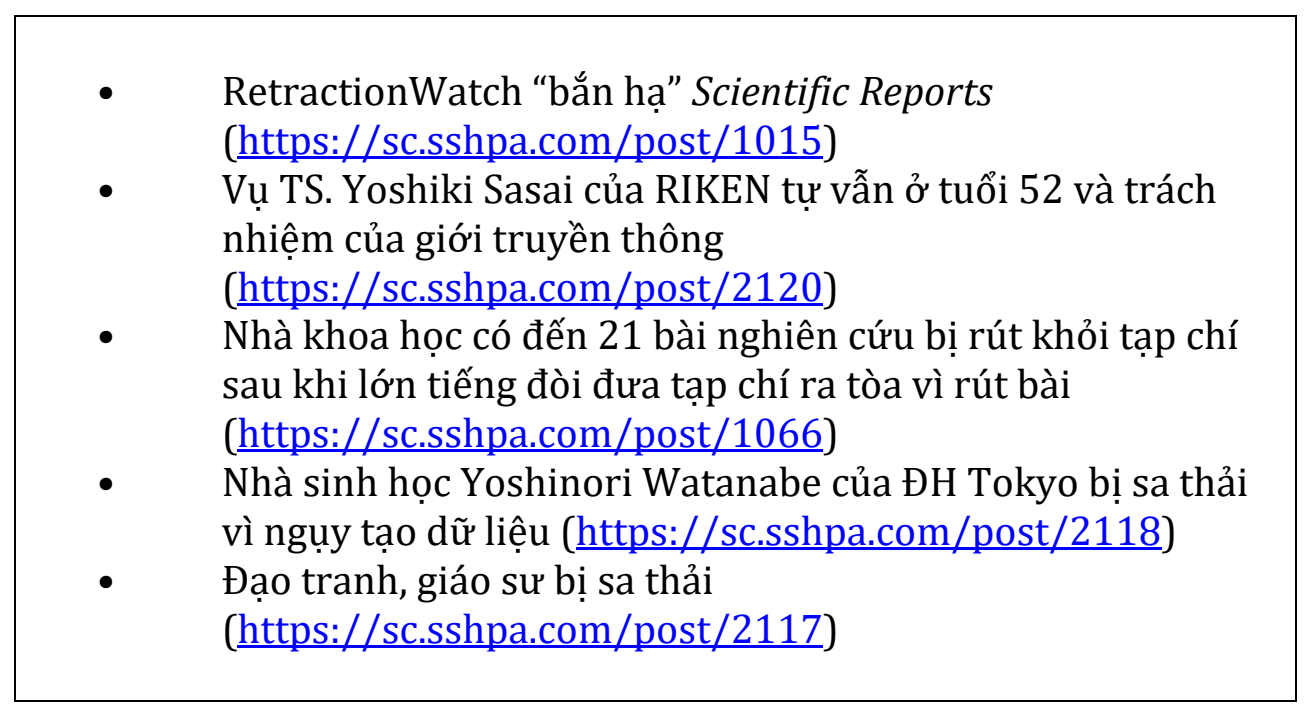

Thậm chí còn có trường hợp đáng tiếc như bài đăng trên một tạp chí rất khó công bố, European Journal of Clinical Nutrition, đã bị rút bởi chính các tác giả chỉ vì một nguyên nhân rất đáng tiếc và khá buồn cười: các tác giả nghiên cứu một loại protein trong sữa, và đăng được bài. Nhưng sau đó, vì ý kiến cộng đồng, cần kiểm tra dữ liệu thì lưu trữ không tốt, bị yêu cầu lấy lại mẫu. Rất tiếc, sau khi qua thời kỳ chăm con thì các bà mẹ lúc trước tự nguyện cung cấp mẫu sữa không còn khả năng cung cấp lại nữa. Các tác giả đành phải chép miệng tự xin rút bài, đầy tiếc nuối; xem: https://sc.sshpa.com/post/1053.

Tại Việt Nam, có thể tham khảo hai bài nghiên cứu gần đây: "Academic integrity in higher education: The case of plagiarism of graduation reports by undergraduate seniors in Vietnam" (Tran, Huynh \& Nguyen, 2018) và "Student plagiarism in higher education in Vietnam: an empirical study" (Do Ba et al., 2017) để thấy được sự nghiêm trọng của vấn đề "đạo" trong giáo dục và khoa học.

\subsection{Các vấn đề nổi bật}


Một số vấn đề nổi lên trong thời gian gần đây trong cộng đồng NCKH quốc tế là:

- Authorship: Accountability vs. Credit

- Falsification

- Fabrication

- Plagiarism (bao gồm cả self-plagiarism)

Những vấn đề này hiện nay hệ thống nghiên cứu KHXH\&NV trong nước cũng vấp phải, ở một số khía cạnh còn gai góc và thách thức hơn.

Điều quan trọng nằm ở chỗ chúng sinh ra không phải vì thiếu nhận thức, hay thiếu quy định, hoặc thiếu nỗ lực truyền thông khoa học. Chính vì thế mà chúng ngày càng trở nên tinh vi, phức tạp, ăn sâu, và dai dẳng hơn.

Vụ điển hình mới nhất (tháng 9-2018) là Brian Wansink, ngôi sao của Cornell, người vừa bị rút 6 nghiên cứu do falsification và fabrication, và sau đó buộc phải từ chức và nghỉ hưu non: https://sc.sshpa.com/post/4304. Thực ra, sự việc bắt đầu từ việc một số chuyên gia quan sát thấy hành vi "salami slicing" và p-hacking, HARKING của Wansink.

Trước đó, thì Yoshinori Watanabe là nhà sinh học tiếng tăm của Đại học Tokyo, với khoảng 120 công bố quốc tế, thậm chí trên các tạp chí mạnh nhất thế giới như Nature, Science, NEJM, Cell, EMBO Reports, v.v..: và 8000 trích dẫn theo dữ liệu của Scopus (https://www.scopus.com/authid/detail.uri?authorId=22036982000), bị sa thải. Ông bị rút 5 bài mạnh trên Nature, Science và $E M B O$, do nguyên nhân "doctoring data" (https://sc.sshpa.com/post/2118).

Danh sách các ví dụ sụp đổ thần tượng vì vi phạm đạo đức và liêm chính khoa học ngày càng dài. Việc thường xuyên theo dõi các trường hợp cũng rất cần thiết; vì thường chúng sẽ dẫn đến các thay đổi quy tắc đạo đức, bổ sung quy định, chế tài, v.v..

\section{Bây giờ nói về phẩm giá của những tác phẩm hang nhất:}

Theo Virginia Gewin, trên Nature: "How to write a first-class paper" ngày 28-2-2018 (Gerwin, 2018), thì:

- Thông điệp chính của kết quả nghiên cứu phải được chuyển tải rõ ràng, mạch lạc. Để tránh bị đứt mạch, nên chú ý đưa dữ liệu và những tính toán không cần nằm trong nội dung vào phụ lục. Giữ cho nội dung chính tập trung vào thông điệp mạnh nhất, đáng chú ý nhất của kết quả. Thảo luận phải vững vàng. Luôn tồn tại một ranh giới mong manh giữa việc đoán biết ảnh hưởng của kết quả và bằng chứng rõ rệt về ảnh hưởng. Trước 
tình huống đó, không nên quá lan man về phía chưa rõ ràng, và khống chế mức độ thảo luận vừa phải, dè dặt và tỉnh táo.

- Thượng tôn cấu trúc. Cấu trúc mà sai, chẳng thể có kết quả tốt. Đặc biệt quan trọng là cấu trúc hướng độc giả tới một mệnh đề kết quả quan trọng nhất. Mọi thứ xoay quanh đó. Đồng thời, cần dẫn dắt độc giả đủ tốt đi đến điểm họ sẵn sàng đón nhận lập luận và kết quả khoa học. Cấu trúc cần làm được việc ấy. Tựa đề bài phải làm được việc quan trọng nhất ấy.

- Trình bày vấn đề với mức độ tự tin tốt nhất. Cụ thể, phải mạch lạc chỉ ra: "Điểm mới đáng chú ý là gì". Thường các tác giả không đủ tự tin về kết quả, nên giọng văn mang tính chất "phòng thủ" hoặc đi kèm theo quá nhiều điều kiện ràng buộc mức độ tin cậy của kết quả. Chúng gây cảm giác kết quả kém tin cậy, và tác giả không dám chắc về công việc của mình.

- Cẩn thận với những danh từ nửa sống nửa chết "zombie nouns". Hầu hết các đoạn văn tẻ nhạt, nặng nề, khô khan và trừu tượng.

- V Vứt bớt đi những thứ tạo nên xu hướng lạm dụng lối nói bóng bẩy, hoa mỹ, rườm rà. Mục tiêu của nghiên cứu là công bố kết quả khoa học, chứ không phải tô vẽ văn cảnh.

- C Cần biết cách hướng đến công chúng rộng rãi, chứ không chỉ thỏa mãn những người gác cửa ấn phẩm.

\section{Rà soát các nội dung của bản thảo}

\subsection{Dẫn nhập}

Kiểm tra độ hợp lý của bối cảnh tạo nên vấn đề. Thường sau một lượt viết bản thảo dài ngày, quay lại phần mở đầu sẽ có những phần, hoặc logic mở đầu bị "sái". Đây là lúc chỉnh sửa, thay thế hoặc thậm chí bỏ hẳn.

Trong một số trường hợp có "câu chuyện" thì cũng là lúc để tính toán sao cho lựa chọn câu chuyện nào tiêu biểu để có được ấn tượng ban đầu hiệu quả nhất với ban biên tập và phản biện. (Về lâu dài là với độc giả và cơ hội được tái sử dụng qua các trích dẫn nghiên cứu về sau.)

\subsection{Rà soát tổng quan lý thuyết liên quan}

Các lý thuyết và hướng dẫn sao cho việc rà soát tổng quan lý thuyết (literature review) đạt hiệu quả tốt tương đối sẵn trên Internet và có chất lượng tốt. Tuy nhiên, từ góc độ người sản xuất bản thảo, việc rà soát sẽ giúp củng cố vài yếu tố quan trọng:

- L Logic tổng thể của các vấn đề được rà soát, các tài liệu sử dụng trong mỗi vấn đề đó.

- Cân đối giữa các loại tài liệu: siêu ảnh hưởng, rất có ích với bài, và nghiên cứu mới giàu tiềm năng. Điểm này ít tác giả hướng dẫn rà soát tài liệu nói đến. Nhưng lại là thực tế và có tác dụng tốt.

- Phương pháp rà soát tổng quan lý thuyết. Hiện tại, thường người ta chỉ ám chỉ 2 tiếp cận chính: a) “Chronology” (theo thời gian, ví dụ: Katz, 2003); b) 
"Thematic review" (theo chủ đề, ví dụ: Vuong \& Napier, 2014). Tuy nhiên, đây không phải tất cả. 'Literature review' hoàn toàn có thể tiếp cận theo hướng data có cấu trúc. Nghĩa là, lượng hóa lượng data định tính để tìm hiểu tính hợp quy tắc thống kê của các văn bản nghiên cứu.

- Kết nối của phần review đến câu hỏi nghiên cứu, góc tiếp cận vấn đề và phương pháp để giải quyết. Các đoạn chuyển mạch sau khi kiểm tra tốt sẽ mềm, mượt và tự nhiên.

Có thể tham khảo thêm bài "Viết bài phê bình khoa học và văn bản rà soát tổng quan lý thuyết" tại https://sc.sshpa.com/post/1038.

Tựu chung, kết nối với lý thuyết là một công việc quan trọng, bắt buộc và có rất nhiều ý nghĩa đối với người làm nghiên cứu nói chung, và tác giả một $\mathrm{CBQT}$ nói riêng. Rà soát và kết nối tốt tạo nên sự vững chãi trong các lập luận về sau, gây mối thiện cảm về nghiêm túc tiến hành viết khoa học, hỗ trợ cho BBT và người phản biện hiểu tác giả, và đặc biệt có ích đối với độc giả về sau. Có một quy luật được quan sát thấy khá rõ: các $\mathrm{CBQT}$ có phần rà soát lý thuyết tốt và thuyết phục cũng thường được đọc và trích dẫn nhiều hơn.

\subsection{Logic và hình thức trình bày kết quả}

Rốt cục, chúng ta vẫn phải trình bày mọi thứ ra giấy:

- $\quad$ Kết nối logic của các kết quả chính

- S Sử dụng Bảng / hình / thống kê / CSDL để thể hiện căn cứ của lập luận và đồng thời tăng tính trực quan đối với độc giả.

- Kiểm tra mức độ phát biểu về kết quả (vừa đúng mực, có bằng chứng ủng hộ, không ngụy biện cho các điểm yếu)

- K Kiểm tra khả năng ngụy biện logic hoặc mâu thuẫn nội tại của kết quả (do nhiều nguyên nhân, chủ quan hay khách quan). Đừng hy vọng rằng ban biên tập và phản biện sẽ bỏ qua, vì đó là một trong những nội dung rà soát chính của họ.

- Các "điểm nhấn" và quan hệ với abstract / summary. Một số còn yêu cầu có phần nói riêng về đánh giá tự thân của tác giả về giá trị của công việc; ví dụ, phần "Significance for public health" (Vuong, 2017b) của nghiên cứu y xã hội, và ngày nay các tạp chí mạnh nhất đều có xu hướng đòi hỏi phần này, như Science, Nature, PNAS, The Lancet, v.v..

- $\quad$ Nêu giới hạn của kết quả (điều kiện kiểm soát kết quả, khả năng tác động). Một kinh nghiệm cá nhân, trước khi chấp thuận đăng bài (Vuong, 2016) các cây bút phản biện nhất mực yêu cầu phải "thành khẩn khai báo" các nhược điểm của kết quả, kèm theo điều kiện khả dĩ làm thay đổi kết quả. Sau khi tiến hành công việc này rất cẩn thận, thực chất chỉ mất chừng 1 giờ đồng hồ, thì tất cả đồng ý đăng luôn. Quyết định của họ khiến có cảm giác kỳ lạ: Dường như họ thích nhất phần khai báo nhược điểm!

\subsection{Tính thuyết phục của "thảo luận"}


Đây là một trong những công việc thú vị, nhưng cũng mệt, và không dễ:

- Đối chiếu và so sánh tính tương thích của kết quả là một nội dung quan trọng của thảo luận học thuật.

- Dự báo phạm vi ảnh hưởng, các điểm dừng của ảnh hưởng, chỗ có thể thay đổi bản chất (vd, ngưỡng).

• Một vài cấu trúc quen thuộc: "Nếu... thì...”; "Không những... mà còn...”; "Một mặt... mặt khác...”; "Mặc dù... nhưng...”; "Sự kiện... được xác nhận qua đặc tính..., nếu nhóm điều kiện... được đảm bảo".

- $\quad$ Ngụ ý của kết quả đặc biệt và vị trí trong kết quả tổng thể (thường thì ở phần thảo luận mới có điều kiện làm kỹ thế nào là 'striking').

- Nêu giới hạn của kết quả: nên thành thực và dành thời gian suy nghĩ về những giới hạn/hạn chế của kết quả. Các giới hạn này có thể nó sẽ mở đường cho các nghiên cứu tiếp theo. Thậm chí có thể dẫn đến cơ hội hợp tác, nếu hạn chế đó có khuynh hướng là do nguyên nhân thiếu hợp tác mà tồn tại. Thực tế là thế này: Người dám bàn về điểm yếu của mình là người mạnh, chứ không phải người yếu.

\subsection{Nghĩ đến người đọc}

Khi bận bịu với rất nhiều công đoạn của công việc nghiên cứu và trình bày nghiên cứu, thường thì chúng ta quên mất độc giả. Và điều này khá tai ương, vì họ chính là raison d'être của nghiên cứu, và ban biên tập hay phản biện - những người quyết định số phận của tác phẩm - cũng chính là độc giả!

Sự hấp dẫn với độc giả chính là yếu tố gây ra ảnh hưởng của tác phẩm. Điển hình là nghiên cứu viết theo phong các tường thuật, kể chuyện gần gũi thường được công bố trên các tạp chí có HSTĐ cao hơn, được đọc nhiều hơn, và có xu hướng được trích dẫn nhiều hơn (Hiller, Kelly \& Klinger, 2016).

\subsection{Rà soát việc đảm bảo hiệu quả trích dẫn}

Quy tắc chung nhất và đáng quan tâm nhất: đầy đủ thông tin như năm xuất bản, tạp chí, số volume, issues, ngày truy cập và đặc biệt là có số DOI thì còn tốt hơn nữa. Chuẩn cao nhất: tăng xác suất có thể tìm và đọc được tác phẩm được trích dẫn nếu ban biên tập, người bình duyệt và độc giả cần tra cứu, dẫn chiếu. Để đạt chuẩn này thì nên trích dẫn các nguồn gốc với số DOI, URL đầy đủ (tất nhiên cũng có nhiều tạp chí chất lượng tốt, thậm chí trong danh mục ISI WoS SCIE hay SSCI, mà hiện vẫn chưa đăng ký số DOI cho các bài xuất bản).

Các khía cạnh khác đáng quan tâm của trích dẫn:

- Q Quy tắc phổ biến trong KHXH\&NV: trích dẫn cân bằng giữa các viewpoint.

- Trích bên trong thân bài sao cho hợp lý, ăn khớp, dễ hiểu và có tác động lên suy nghĩ của độc giả (là đồng nghiệp). 
- Vấn đề "cosmetic": trích dẫn phải làm giàu nội dung, giàu quan điểm, tăng sức mạnh cho lập luận, chứ không nên qua loa làm đẹp.

- S Số lượng trích dẫn: bài tổng thì khoảng 90-120 trích dẫn, bài công bố kết quả nghiên cứu thì khoảng 30 trích dẫn.

- Nên trích dẫn ai, cái gì, và "độ mới" cần thiết? Ví dụ phải có trích dẫn người đầu tiên và người gần đây nhất bàn luận về vấn đề của bài.

- Yêu cầu trích dẫn bổ sung trong lúc bình duyệt: có những chuyên gia bình xét rất tận tâm nhiều khi cung cấp cả những tài liệu nên đọc và trích dẫn.

- Trích dẫn "cưỡng bức": ví dụ ban biên tập hoặc phản biện yêu cầu trích dẫn một bài thì hầu như rất khó từ chối trích dẫn, nhất là với những người chưa có thành tựu dày dặn và cơ hội công bố mong manh, ít lựa chọn. Điều này không hẳn tốt, vì có khuynh hướng dẫn đến lạm dụng quyền lực của biên tập và phản biện để làm tăng lượng đếm trích dẫn của họ (vốn là một thước đo về ảnh hưởng của xuất bản phẩm). Tuy nhiên nói là xấu hoàn toàn thì cũng không phải, vì có nhiều trường hợp, yêu cầu là chính đáng.

Một số thông tin trình bày ở trên phần nào làm rõ hơn nội dung công việc, và hướng đến hành động cụ thể trong quá trình viết (cũng như biên tập) khoa học. Ngoài ra, Hộp 4 cũng cung cấp thêm một số thông tin liên quan đến nguồn bổ sung dữ liệu cho quá trình ra quyết định của tác giả.

Hộp 4. Một số thông tin tham khảo bổ sung cho quá trình CBQT

Các giai đoạn của quá trình công bố nghiên cứu, được mô tả qua 8 bước căn bản: https://sc.sshpa.com/post/1073

Hệ thống CSDL tạp chí, và hệ số tác động JIF, CiteScore cung cấp nhiều thông tin cho các tác giả viết bài lựa chọn: https://sc.sshpa.com/post/1108

Hoạt động theo dõi rút bài "Retraction" và tìm hiểu các bài học về liêm chính học thuật: https://retractionwatch.com/

Kinh nghiệm trong tham gia bình duyệt và biên tập hỗ trợ rất nhiều cho việc viết bản thảo tốt: $\underline{\text { http://asapbio.org/mcdowell-ecrs }}$

Xu hướng dữ liệu mở toàn cầu (Vuong, 2017b) cũng như việc hợp tác đứng trước một số vấn đề kỹ thuật sâu, ví dụ Nguyễn \& Vương (2007). Thường quá trình hợp tác mang lại những lợi ích vượt trội, nhiều khi có tính chất quyết định. 
Các phần tiếp sau đây đóng góp củng cố nhận thức của tác giả về khả năng hoàn thành công việc, $\mathrm{CBQT}$ thành công và cân bằng giữa công việc nghiên cứu và đời sống hàng ngày.

\section{Vượt qua các rào cản nội tại}

Trong các khó khăn thì một số rào cản có tính chất nội tại và cá nhân, gây khó khăn cho quá trình chuẩn bị, hợp tác và hoàn thành $\mathrm{CBQT}$. Cụ thể một số thường gặp được trình bày dưới đây, vì chúng đáng được quan tâm do ảnh hưởng đến năng suất và chất lượng nghiên cứu.

\subsection{Nỗi sợ thất bại}

Nỗi sợ thất bại là một ám ảnh phổ biến, có thể đến từ những nguyên nhân như sợ thất bại khiến cho mất tự tin, hay không chịu được cảm giác đã làm rất vất vả mà vẫn bị chê, hoặc sự đánh đồng thất bại CBQT với sự kém cỏi bản thân.

Vì tất cả những cảm giác và nhận biết tiêu cực trên đều sai, do đó đáng ra nỗi sợ này không nên tồn tại.

Cách tốt nhất để vượt qua nỗi sợ: bắt tay vào hành động.

\section{2. Đắm đuối trong cái cũ}

Một rào cản nữa cũng rất lớn về tâm lý là "tiếc công". Điều này dễ hiểu, một khi công sức bỏ ra đã nhiều, và kỳ vọng của cá nhân hoặc nhóm nghiên cứu lớn vào một hướng, hay suy nghĩ ban đầu.

Tương tự như vậy là tiếc những gì mình đã biết về một phương pháp cũ, phần mềm quen thuộc, chương trình soạn thảo đã thành thạo, hoặc thậm chí là nhóm đề tài đã có được thành tích đáng nể, đã được khen ngợi.

Tác động lâu dài của việc đắm đuối này khá tai hại:

- Không muốn, và cuối cùng là không thể, tiếp cận công nghệ mới

- Né tránh sự thật về thực tế không được như kỳ vọng, và né tránh quyết tâm thay đổi cách tư duy, thậm chí toàn bộ bài toán, dữ liệu

- Chìm dần vào khuynh hướng "dễ làm, khó bỏ"

- Bằng lòng với những thứ đã có, những loại kết quả dễ dự báo, không gai góc

- Dành rất nhiều thời gian để ngợi ca quá khứ hào hùng của bản thân

Những khuyết nhược này có thể được hạn chế nhờ bài học căn bản về lợi của kinh tế và kinh doanh. 
Thứ nhất, đó là bài học "cắt lỗ" trong giao dịch đầu tư trên thị trường chứng khoán. Thứ tài sản không thể sinh lãi trong khoảng thời gian có thể dự báo, thì nên loại ra khỏi rổ tài sản.

Thú hai, là bài học về tinh thần khởi nghiệp của Silicon Valley: "Fail Fast, Fail Often". Làm quen với thất bại là một nội dung rất căn bản của nghiên cứu KH.

\subsection{Thiếu đức khiêm nhường}

Giới khoa học được gọi "thầy" và tự xưng "thầy". Xung quanh các học hàm, học vị, chức danh, không hiếm những đại ngôn, thậm xưng. Đó là sự phản chiếu căn bệnh tự yêu bản thân thái quá, và đặt "cái tôi" của mình lên trên thiên hạ. Hậu quả là sự khan hiếm đức khiêm cung, tinh thần học hỏi.

Đến quân vương có đức độ xưa kia còn biết lối khiêm nhường tự xưng "quả đức chi nhân” (寡德之人) nhưng đến ngày nay lại có những người có danh xưng lớn như giáo sư, tiến sỹ lại có thể nói thế này:

"Trình độ cao như tôi, sao lại phải phản biện. Không phản biện gì hết, cắt của tôi một chũ cũng phải hỏi."

Với kiểu tư duy và thái độ như thế, thực sự chúng ta có cần tạp chí nghiên cứu không? Có cần hệ thống biên tập không? Có cần phản biện không? Và cuối cùng: Có bao giờ bằng được một phần nhỏ công trạng khoa học của thế giới không?

Một cách để hạn chế: "Low ego, high output" hay như cách nói dân gian lại còn đơn giản, dễ hiểu và quen thuộc hơn: "Thắng không kiêu, bại không nản".

\subsection{Hạn chế năng lực tổ chức và hợp tác nghiên cứu}

Do độ tập trung cao và nhiều hướng nghiên cứu có bản chất hẹp, sâu, năng lực tổ chức nhóm nghiên cứu, và điều phối hợp tác giữa các nhóm có khả năng tạo ra lợi ích tri thức lẫn nhau, hiện nay đang bị hạn chế.

Sự hạn chế này dẫn đến một vài hệ quả như: a) Việc triển khai các phương pháp mới sẽ gặp nhiều thách thức hơn; b) Những vấn đề lớn thường khó khăn và kéo dài; $c$ ) Nguồn lực (kể cả tài chính) bị hạn chế; và, d) Suy kiệt sức lực trong những dự án quy mô lớn.

\subsection{Bẫy "chất lượng đủ tốt"}

Trong nghiên cứu về hành vi tổ chức, Jim Collins có đưa ra quan điểm và lập luận rất thuyết phục: "Tốt là kẻ thù của vĩ đại". 
Đối với NCKH thì không đợi Jim Collins, mà từ lâu các nhà khoa học đã có cơ chế tự vấn, tự phản biện, tự thách thức bản thân, và tự vượt lên trên các thành tựu cá nhân. Việc các nhà $\mathrm{KH}$ có lương tri tự bác bỏ chính mình không phải là hiếm. Việc nhận sai lầm, thậm chí tự công khai sai lầm của mình trong khi toàn bộ thế giới chưa ai biết đến cũng đã thành bài học cơ bản và niềm khâm phục, kính trọng của toàn thế giới khoa học với cậu bé Nathan Georgette (2009). Nathan Georgette bộc bạch rất tuyệt vời về lý do tự mình đề nghị rút bài của mình (DOI: 10.1371/journal.pone.0004168) trên tạp chí rất uy tín PLoS ONE (Q1 ISI Web of Science và Scopus, 2017 IF 2.766):

“Các quyết định quan trọng đều dựa trên các bài báo nghiên cúu đủ loại. Đùng để quan niệm về tầm quan trọng hay tầm ảnh hưởng của bài nghiên cúu là cái có để cho một sai sót đáng kể trôi đi trong quên lãng; bạn không bao giờ biết được khi nào thì một nhà nghiên cúu khác bi ảnh hưởng bởi kết quả đã công bố của bạn".

-Nathan Georgette

Tuy nhiên, dường tình hình chung lại có khuynh hướng bị rơi vào bẫy "chất lượng đủ tốt". Bẫy này do quá trình cố gắng đạt sản lượng yêu cầu, và để dễ hoàn thành thì chọn chất lượng vừa đủ mức đạt chuẩn. Nếu nó xảy ra ở diện rộng, nền khoa học sẽ không thể cất cánh được.

Không riêng Việt Nam, mà nền khoa học mạnh-đang trên đà tranh giành vị trí số 1 thế giới-của Trung Quốc cũng đối mặt với bẫy này. KHXH\&NV Trung Quốc hiện nay cũng thừa nhận chưa bắt nhịp được với tốc độ phát triển của KHTN\&CN (The Economist, 2018).

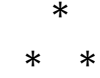

Các vấn đề vừa trình bày không khó để nhận biết. Trên thực tế, một số cũng trở thành đề tài thường xuyên của báo giới cũng như trong các cơ sở nghiên cứu, giáo dục. Thế nhưng, cho dù nhận thức và chỉ ra căn nguyên rõ ràng, thì giải quyết chúng cũng không hề dễ. Đó là vì thay đổi dù rất tích cực nhưng ở một vài nhóm lẻ tẻ không thể tích lũy đủ để vượt qua sức ì, và kể cả kháng cự thay đổi. Ngay việc CBQT, một yêu cầu cấp thiết đã được nhận thấy ở NAFOSTED hơn 10 năm nay, nhưng trong KHXH\&NV đến nay vẫn tiếp tục có nhiều ý kiến tranh cãi theo hướng làm chậm quá trình thay đổi.

\section{Bối cảnh thay đổi của thế giới}

Trong khi đó, tình hình thế giới đang thay đổi vô cùng nhanh chóng. Hiệu quả đầu tư khoa học được cân nhắc và thảo luận ở khắp mọi cơ quan chính sách, quản lý, tài trợ và tổ chức triển khai công việc khoa học-giáo dục.

Các bảng xếp hạng các cơ sở giáo dục là một ví dụ tiêu biểu. Chúng sử dụng các CSDL như ISI Web of Science và Scopus để tiến hành đo lường năng suất và ảnh hưởng của kết quả khoa học lên xã hội, đời sống con người và cả chính hệ thống khoa học. 
Các khuynh hướng khoa học nổi bật như dữ liệu mở, phản biện mở và minh bạch 100\% (thậm chí sau khi xuất bản theo cách của F1000Research, Wellcome Open Research, ${ }^{8}$ Bill and Melinda Gates Foundation ${ }^{9}$ ), đánh giá cộng đồng, "Plan S", v.v.. đang khiến cho thế giới khoa học nói chung, và hệ thống tài trợ cho hoạt động khoa học nói riêng, thay đổi liên tục.

Thế giới kết nối ở quy mô cực lớn, và ngày càng sâu, cùng với tốc độ Internet, các tài nguyên dựa trên và phục vụ chính hạ tầng Internet đang thúc đẩy sự hình thành của kỷ nguyên cách mạng công nghiệp 4.0. Có lẽ, một trong những bộ phận chịu ảnh hưởng và được thụ hưởng trực tiếp, nhanh nhất chính là giới $\mathrm{NCKH}$, cụ thể là bản thân các tác giả. Ảnh hưởng có thể lớn tới mức mà Holly Else trong một bài phân tích về "Plan S" trên Nature cho rằng thay đổi mới báo trước sự cáo chung của kiểu công bố các tạp chí ‘đóng' chỉ dành cho người đăng ký (Else, 2018).

Hình 7. Tăng trưởng xuất bản mở

\section{GROWTH OF OPEN ACCESS}

In 2016, journals made $18.9 \%$ of papers open immediately on publication, up from $11.5 \%$ in 2012.

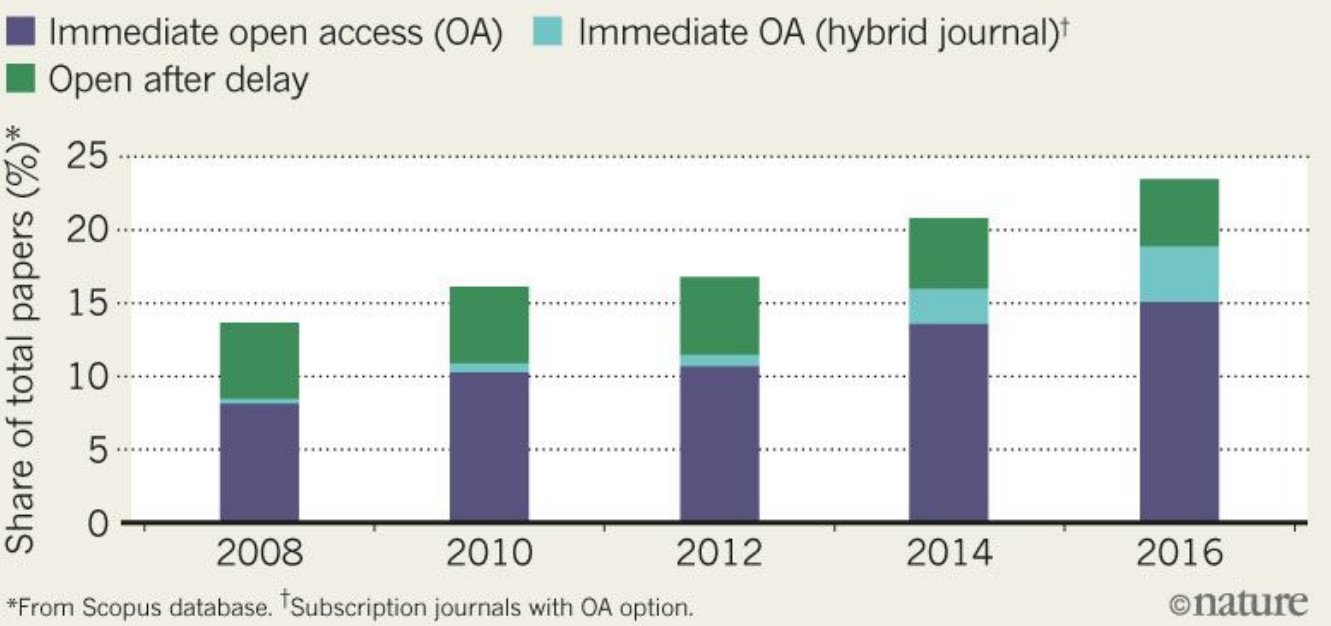

Source: UUK (2017)/BMC Med. 10, 124 (2012).

Khả năng kết nối đó còn dẫn đến cả thực tế công việc bình duyệt khoa học thầm lặng bây giờ cũng ngày càng trở nên minh bạch, và tiến tới tất cả hồ sơ bình duyệt có thể được tập trung hóa về CSDL của Publons. Publons là một startup về CSDL phản biện ra đời ở một trường đại học New Zealand, nhưng khi lớn mạnh đã được Clarivate Analytics thâu tóm, và nhanh chóng kết nối vào CSDL ISI Web of Science, cũng như hệ thống quản lý biên tập khoa học ScholarOne Manuscripts ${ }^{\mathrm{TM}}$ của Clarivate. Bây giờ, hàng năm họ thống kê dữ liệu, và đánh giá khối lượng công việc của hàng triệu người

${ }^{8}$ Tham khảo: https://wellcomeopenresearch.org/

${ }^{9}$ Tham khảo: https://gatesopenresearch.org/ 
làm nghiên cứu toàn cầu, rồi công bố các báo cáo về tình trạng chung của công tác bình xét khoa học. Đó là điều không tưởng cách đây chỉ chưa tới 10 năm.

Chỉ tính riêng việc xây dựng các kho dữ liệu mở trên mạng, cũng như hệ thống Preprints Servers lưu trữ bản thảo, ngày nay thế giới có rất nhiều, và vẫn không ngừng tăng lên: Dryad, Dataverse, UK Data Archive, Figshare, OSF, Zenodo, arXiv... Tất cả đều miễn phí. Mọi thứ đều minh bạch, tới mức một file được tải lên, cho dù tác giả xóa đi, thì dấu vết của hành động xóa vẫn còn nguyên.

Xét cho cùng, tất cả những thay đổi ấy đều có phần hướng đến một đội ngũ cốt lõi: các tác giả khoa học. Chúng góp phần thúc đẩy sản lượng công bố khoa học.

Bên cạnh đó, những thay đổi hiện đại cũng đặt ra thách thức với việc tìm kiếm chất lượng nghiên cứu đỉnh cao; đó là vì sự tồn tại khách quan mâu thuẫn giữa yêu cầu về sản lượng với đòi hỏi tập trung cho chất lượng.

Đại diện của lực lượng đang lên như ĐH Thanh Hoa cho thấy rõ quan điểm về việc này, rất đáng để chúng ta suy ngẫm:

"It's good for short-term results, but not for really big things, for unorthodox thinking. Too many people have the attitude of followers. They're not entrepreneurial enough. I say: Start some new field. Don't care too much about recognition from peers. Risk your whole career."

— Yang Bin, Phó CT Đại học Thanh Hoa (The Economist, 2018).

Những thay đổi trên thế giới, nhất là ở các nước phát triển lâu đời phương Tây, còn có thể được xem là xa xôi. Nhưng điều đang thay đổi ngay trong giới tác giả và biên tập khoa học ở nước láng giềng Trung Quốc thì sẽ khiến cộng đồng KH Việt Nam phải suy ngẫm và trăn trở, và đổi mới với tinh thần cầu thị.

\section{* Thay lời kết:}

Có vài điều giúp kết luận tài liệu trợ giúp nghiên cứu này một cách ngắn gọn như sau.

Trước tiên, điều đáng nói nhất ở một tác phẩm chính là bản thân giá trị thông tin, hiểu biết và đóng góp thay đổi nhận thức-hành vi của tác phẩm. Chúng không nên bị che khuất bởi tên tạp chí, JIF hay CiteScore, nhà xuất bản, thậm chí cả tính tân kỳ, hay sự uy nghi của phương pháp!... hay bất kỳ loại "bao bì" nào tương tự. (Phân tích hai trường hợp được sử dụng nhiều cho các nhà nghiên cứu: Vuong \& Tran, 2009; Vuong, 2014.)

Thứ hai, bản chất đáng nói nhất của công việc khoa học, ở cả 3 vai: authorreviewer-editor, là tư duy, cải thiện chất lượng tư duy, và tự hiệu chỉnh sai lầm. Trong đó tự hiệu chỉnh sai lầm được coi là "con ngựa cày" (workhorse) của giới khoa học trên cánh đồng khoa học. 
Thứ $b a, \mathrm{NCKH}$ dù hay, khó, lý thú hay phức tạp đến đâu, cũng là một phần của đời sống xã hội. Do đó, các khuynh hướng khoa học bị ảnh hưởng mạnh bởi những thay đổi của đời sống con người toàn cầu, từ ý niệm đạo đức, vấn đề bình đẳng giới, trào lưu đòi hỏi minh bạch, tính công bằng hoạt động con người, và gần đây nhất là đòi hỏi giá trị trả lại cho xã hội qua "chính sách mở" và yêu cầu hoạt động SciComm (xem tranh vui Hình 8).

\section{Hình 8. Nhu cầu SciComm}

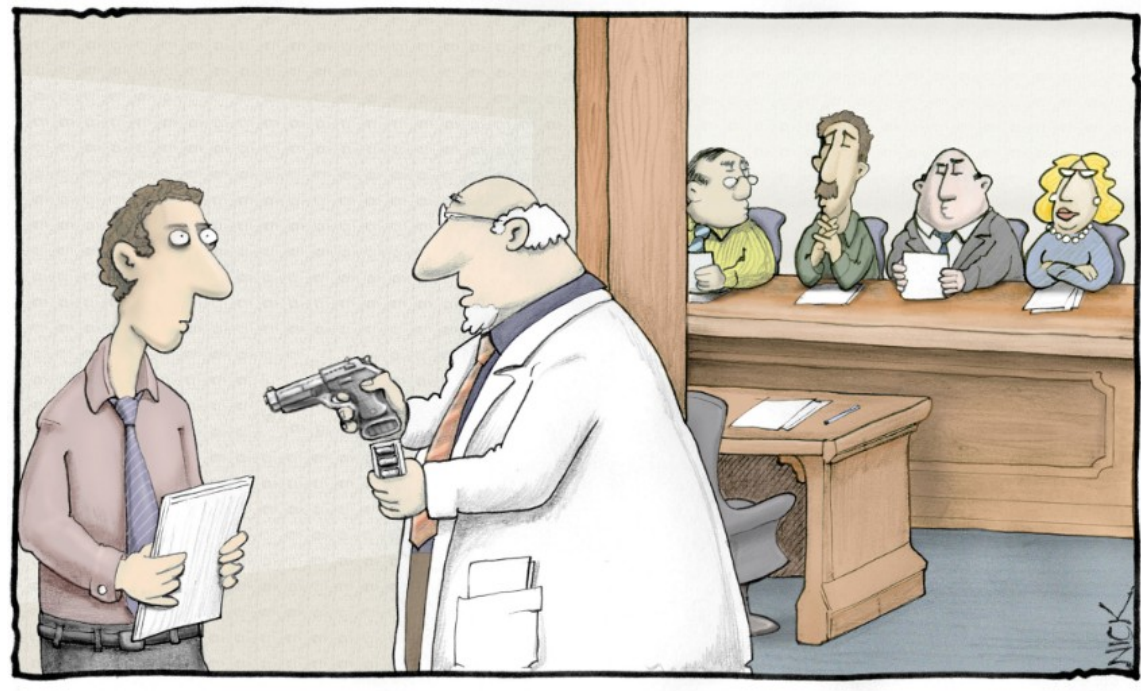

"Change of plan. The policymakers say they're only willing to listen to the science if we can present our ideas in simple bullet-point format."

Cuối cùng, những yếu tố này sẽ được phản ánh vào chất lượng hoạt động khoa học, dù nhà nghiên cứu đứng ở vai nào trong các vai tác giả, phản biện hay biên tập.

\section{REFERENCES}

Banks, D. (2018). Thoughts on publishing the research article over the centuries. Publications, 6(1), 10, DOI:10.3390/publications6010010.

Borja, A. (2015). Writing the first draft of your science paper - some dos and don'ts. Elsevier Connect. Retrieved from https://www.elsevier.com/connect/writinga-science-paper-some-dos-and-donts.

Bui, H.T., \& Tuan, A.L. (2017). Climate change impacts on UNESCO World HeritageThe case of Hoi An ancient town. In A. Jones \& M. Phillips (Eds.), Global Climate Change and Coastal Tourism: Recognizing Problems, Managing Solutions and Future Expectations (pp. 191-200). Oxfordshire, UK: CABI International.

Dao, T.V. (2013). A review of "Taking responsibility for tourism". Journal of Sustainable Tourism, 21(6), 934-937. 
Do Ba, K., Lam, Q.D., Le, D.T.B.A., Nguyen, P.L., Nguyen, P.Q., \& Pham, Q.L. (2017). Student plagiarism in higher education in Vietnam: an empirical study. Higher Education Research \& Development, 36(5), 934-946.

Economist. (2018, Nov 17). Seizing the laurels: Tsinghua University may soon top the world league in science research. The Economist. Retrieved from: https://amp.economist.com/china/2018/11/17/tsinghua-university-maysoon-top-the-world-leaguein-science-research

Else, H. (2018). Radical open-access plan could spell end to journal subscriptions. Nature 561, 17-18. DOI: 10.1038/d41586-018-06178-7. Available from: https://www.nature.com/articles/d41586-018-06178-7

Georgette, N.T. (2009). Predicting the herd immunity threshold during an outbreak: a recursive approach. PLoS ONE 4(2), DOI: 10.1371/journal.pone.0004168.

Gerwin, V. (2016). Data sharing: An open mind on open data. Nature, 529(7584), 117-119, DOI: 10.1038/nj7584-117a.

Gerwin, V. (2018). How to write a first-class paper. Nature, 555(7694), 129-130, DOI: $10.1038 / \mathrm{d} 41586-018-02404-4$.

Giang, N. T. (2014). Nostalgia for the new oldness: Vietnamese television dramas and national belonging. Media International Australia, 153(1), 64-72, DOI: 10.1177/1329878X1415300108.

Hartley, J. (2008). Academy Writing and Publishing: A Practical Handbook. United Kingdom: Routledge.

Hiller, A., Kelly, R. P., \& Klinger, T. (2016). Narrative style influences citation frequency in climate change science. PLOS ONE, 11(12), e0167983.

Ho, T.M., Nguyen, H.V., Vuong, T.T., Dam, Q.M., Pham, H.H., \& Vuong, Q.H. (2017). Exploring Vietnamese co-authorship patterns in social sciences with basic network measures of 2008-2017 Scopus data. F1000Research, 6, 1559.

Ho, T.M., Nguyen, T.H.K, Vuong, T.T., \& Vuong, Q.H. (2017). On the sustainability of co-authoring behaviors in Vietnamese social sciences: A preliminary analysis of network data. Sustainability, 9(11), 2142, DOI: 10.3390/su9112142.

Katz, J.A. (2003). The chronology and intellectual trajectory of American entrepreneurship education: 1876-1999. Journal of Business Venturing, 18(2), 283-300, DOI: 10.1016/S0883-9026(02)00098-8.

Kirwan, J. (2017). It's good to have lots of bad ideas. Nature, 548(7668), 491, D0I: 10.1038/nj7668-491a.

Le, T. (2010). Are student flows a significant channel of R\&D spillovers from the north to the south?. Economics Letters, 107(3), 315-317.

Long, G.T. (2012). Viet Nam: Pension system overview and reform directions. In D. Park (Ed.), Pension Systems and Old-age Income Support in East and Southeast Asia (pp. 221-239). Oxfordshire, UK: Routledge.

Minh, P.Q. (2015). In the crossfire: Vietnam and great powers in the emerging East Asian security architecture. In K. Togo \& G.V.C. Naidu (Eds.), Building confidence in East Asia: Maritime conflicts, interdependence and Asian identity thinking (pp. 13-26). New York, NY: Palgrave Pivot.

Napier, N.K., \& Vuong, Q.H. (2013). Serendipity as a strategic advantage?. In Wilkinson (ed) Strategic Management in the 21st Century (pp. 175-199). Westport, CT: Praeger/ABC-Clio. 
Nguyen, V.C. (2017). Do minimum wages affect firms' labor and capital? Evidence from Vietnam. Journal of the Asia Pacific Economy, 22(2), 291-308.

Nguyễn, V.H., \& Vương, Q.H. (2007). Các phương pháp toán học trong tài chính. Hà Nội: NXB Đại học Quốc gia Hà Nội.

Publons. (2018) 2018 Global State of Peer Review. Retrieved from: https://publons.com/static/Publons-Global-State-Of-Peer-Review-2018.pdf (truy cập: 18-11-2018).

Tran, U.T., Huynh, T., \& Nguyen, H.T.T. (2018). Academic integrity in higher education: The case of plagiarism of graduation reports by undergraduate seniors in Vietnam. Journal of Academic Ethics, 16(1), 61-69.

$\mathrm{Vu}, \mathrm{C.B}$. (2017). News media and the neoliberal privatization of education. Policy Futures in Education, 15(1), 129-132.

Vuong, Q.H. (2014). Vietnam's political economy: a discussion on the 1986-2016 period. Working Papers CEB 14-010, Université Libre de Bruxelles.

Vuong, Q.H. (2015). Be rich or don't be sick: estimating Vietnamese patients' risk of falling into destitution. SpringerPlus, 4(1), 529.

Vuong, Q.H. (2016). Impacts of geographical locations and sociocultural traits on the Vietnamese entrepreneurship. SpringerPlus, 5(1), 1189.

Vuong, Q.H. (2017a). Learning to love the reviewer. European Science Editing, 43(3), 83, DOI: 10.20316/ESE.2017.43.001.

Vuong, Q.H. (2017b). Economic benefits and treatment progress as determinants of the sustainability of Vietnamese voluntary co-located patients clusters. Journal of Public Health Research, 6(1), 10-17, DOI: 10.4081/jphr.2017.788.

Vuong, Q.H. (2017c). Survey data on Vietnamese propensity to attend periodic general health examinations. Scientific Data, 4, 170142.

Vuong, Q.H., \& Napier, N.K. (2014). Making creativity: the value of multiple filters in the innovation process. International Journal of Transitions and Innovation Systems, 3(4), 294-327.

Vuong, Q.H., \& Napier, N.K. (2017). Academic research: the difficulty of being simple and beautiful. European Science Editing, 43(2), 32-33.

Vuong, Q.H. (2017b). Open data, open review and open dialogue in making social sciences plausible. Scientific Data Updates (Dec. 12, 2017). Retrieved from: http://blogs.nature.com/scientificdata/2017/12/12/ authors-corner-opendata-open-review-and-open-dialogue-in-making-social-sciences-plausible/.

Vuong, Q.H. (2018). The (ir)rational consideration of the cost of science in transition economies. Nature Human Behaviour, 2(1), 5, DOI: 10.1038/s41562-0170281-4.

Vuong, Q.H., La, V.P., Vuong, T.T., Nguyen, V.H., Ho, M.T., Nguyen, T.H.K., Bui, Q.K., \& Ho, M.T. (2018). Cultural additivity: Behavioural insights from the interaction of Confucianism, Buddhism, and Taoism in folktales. Palgrave Communications, 4, DOI: 10.1057/s41599-018-0189-2.

Vuong, Q.H., Napier, N.K., Ho, M.T., Nguyen, V.H., Vuong, T.T., Pham, H.H., Nguyen, T.H.K. (2018). Effects of work environment and collaboration on research productivity in Vietnamese social sciences: evidence from 2008 to 2017 Scopus data. Studies in Higher Education, 43, DOI: 10.1080/03075079.2018.1479845. 
Vuong, Q.H., \& Tran, T.D. (2009). The cultural dimensions of the Vietnamese private entrepreneurship. The IUP Journal of Entrepreneurship Development, 6(3/4), 54-78.

Vuong, T.T., Nguyen, T.H.K., Ho, M.T., Ho, M.T., \& Vuong, Q.H. (2017). The (in)significance of socio-demographic factors as possible determinants of Vietnamese social scientists' contribution-adjusted productivity: Preliminary results from 2008-2017 Scopus data. Societies, 8(1), 3, DOI: $10.3390 /$ soc 8010003 . 